\title{
Article
}

\section{Transcriptome-Wide Gene Expression Plasticity in Stipa grandis in Response to Grazing Intensity Differences}

\author{
Zhenhua Dang ${ }^{1, *,+}\left(\mathbb{D}\right.$, Yuanyuan Jia ${ }^{1,+} \mathbb{0}$, Yunyun Tian ${ }^{2}$, Jiabin Li ${ }^{1}$, Yanan Zhang ${ }^{1}$, Lei Huang ${ }^{1}$, Cunzhu Liang ${ }^{1}$, \\ Peter J. Lockhart ${ }^{3}$, Cory Matthew ${ }^{4} \mathbb{D}$ and Frank Yonghong Li $^{1}$
}

1 Ministry of Education Key Laboratory of Ecology and Resource Use of the Mongolian Plateau \& Inner Mongolia Key Laboratory of Grassland Ecology, School of Ecology and Environment, Inner Mongolia University, Hohhot 010021, China; jyy773839714@163.com (Y.J.); lijiabinooooo@163.com (J.L.); zyanan419@163.com (Y.Z.); huanglei_1996@163.com (L.H.); bilcz@imu.edu.cn (C.L.); lifyhong@126.com (F.Y.L.)

2 Ministry of Education Key Laboratory of Herbage \& Endemic Crop Biotechnology, School of Life Sciences, Inner Mongolia University, Hohhot 010021, China; yunyuntian412@hotmail.com

3 School of Fundamental Sciences, College of Sciences, Massey University, Palmerston North 4442, New Zealand; P.J.Lockhart@massey.ac.nz

4 School of Agriculture and Environment, Massey University, Palmerston North 4442, New Zealand; C.Matthew@massey.ac.nz

* Correspondence: zhdang@imu.edu.cn; Tel.: +86-1514-802-6396

+ These authors have contributed equally to this work and share first authorship.

Citation: Dang, Z.; Jia, Y.; Tian, Y.; Li, J.; Zhang, Y.; Huang, L.; Liang, C.; Lockhart, P.J.; Matthew, C.; Li, F.Y. Transcriptome-Wide Gene Expression Plasticity in Stipa grandis in Response to Grazing Intensity Differences. Int. J. Mol. Sci. 2021, 22, 11882. https:// doi.org/10.3390/ijms222111882

Academic Editor: Roman Hobza

Received: 9 September 2021

Accepted: 26 October 2021

Published: 2 November 2021

Publisher's Note: MDPI stays neutral with regard to jurisdictional claims in published maps and institutional affiliations.

Copyright: (c) 2021 by the authors. Licensee MDPI, Basel, Switzerland. This article is an open access article distributed under the terms and conditions of the Creative Commons Attribution (CC BY) license (https:// creativecommons.org/licenses/by/ $4.0 /)$.

\begin{abstract}
Organisms have evolved effective and distinct adaptive strategies to survive. Stipa grandis is a representative species for studying the grazing effect on typical steppe plants in the Inner Mongolia Plateau. Although phenotypic (morphological and physiological) variations in S. grandis in response to long-term grazing have been identified, the molecular mechanisms underlying adaptations and plastic responses remain largely unknown. Here, we performed a transcriptomic analysis to investigate changes in gene expression of $S$. grandis under four different grazing intensities. As a result, a total of 2357 differentially expressed genes (DEGs) were identified among the tested grazing intensities, suggesting long-term grazing resulted in gene expression plasticity that affected diverse biological processes and metabolic pathways in S. grandis. DEGs were identified in RNA-Seq and qRT-PCR analyses that indicated the modulation of the Calvin-Benson cycle and photorespiration metabolic pathways. The key gene expression profiles encoding various proteins (e.g., ribulose-1,5bisphosphate carboxylase/oxygenase, fructose-1,6-bisphosphate aldolase, glycolate oxidase, etc.) involved in these pathways suggest that they may synergistically respond to grazing to increase the resilience and stress tolerance of $S$. grandis. Our findings provide scientific clues for improving grassland use and protection and identifying important questions to address in future transcriptome studies.
\end{abstract}

Keywords: comparative transcriptomic analysis; gene expression plasticity; differentially expressed gene; grazing adaptation; Calvin-Benson cycle; photorespiration; Stipa grandis

\section{Introduction}

Grassland covers about $40 \%$ of the total land area worldwide [1]. It plays a crucial role in ecological security by regulating the climate, conserving water resources, preventing wind and water erosion, and in the provision of forage for pastoral production [2-4]. Grazing is the most common land use in grassland regions. Unfortunately, because of long-term inappropriate use, human activities, and adverse natural factors (e.g., warming, drought, and pest damage), grasslands have been extensively damaged, resulting in serious ecological issues. In particular, $74 \%$ of the grassland in northern China has become degraded because of decades of over-grazing and the fact that the region is gradually 
becoming more arid. This has seriously threatened the survival and growth of the grassland vegetation, the local biodiversity, and the livelihoods of local herders.

Grazing affects the availability of resources essential for plant growth, including nutrients, water, and light, while also influencing ground temperatures. The ability of plants to use these resources is altered accordingly. These changes result in the redistribution of materials and energy in plants, thereby affecting herbage growth [5]. Plant phenotypes are influenced by the impact of the environment on the formation of individual traits, including morphological, physiological, or behavioral responses [6,7]. Many previous studies have explored how plant phenotypes are affected by grazing disturbance $[8,9]$. Under continuous grazing disturbance, herbage usually exhibits dwarfism-related characteristics, including decreased height and short internodes, short and narrow leaves, stiff branches, small clumps and seeds, and shallow root distribution [10,11]. These traits ultimately decrease the biomass of an individual plant and the whole community. A comparison by Louault et al. [8] of the functional traits between plants in a grassland area that has been grazed for 12 years and plants in a grassland area with no grazing indicated that among 22 traits (e.g., leaf economy, root morphology, reproductive characteristics, and phenology), seven traits related to plant height were significantly affected by grazing. In sward-forming grasses, responses to grazing have been referred to as tiller size-density compensation, a phenomenon which operates to optimize sward leaf area index through a higher density of smaller shoots in conditions of more intense grazing and a lower density of larger shoots under laxer grazing. Under more extreme grazing intensity, both the size and density of shoots are reduced [12]. In clump- or tussock-forming grasses, a phenomenon similar to tiller size-density compensation can occur at the tussock level, with grazing altering the size and density of tussocks [13].

At the physiological level, grazing has been found to induce a series of changes in mesophyll cells, including changes to levels of expression and activity of photosynthetic enzymes, chlorophyll content, electron transport capacity, and hormone regulation [14,15]. More specifically, the physiological processes of the photosynthetic system, carbon assimilation capacity, and water use efficiency are substantially enhanced in grazed plants in response to defoliation disturbance and other stress conditions $[16,17]$. Moreover, several biological events, such as cell division, meristem elongation, leaf growth, and tillering, are promoted. These changes have been linked with recovery from damage incurred by grazing $[15,18,19]$ while some physiological responses to grazing may not help plant growth. Increased photosynthetic activity can result in the over-accumulation of metabolic byproducts, such as reactive oxygen species and free radicals, and these can damage membrane lipid structures and disrupt water and ion homeostasis in plant cells [20]. However, during the regrowth of herbage after grazing, the accumulation of large amounts of osmoprotectants (e.g., proline and betaine) and the activation of the reactive oxygen scavenging system has been observed. Both could help to eliminate and/or minimize the toxic effects of the metabolic byproducts $[15,21,22]$. Additionally, the feeding behavior of livestock has been found to stimulate plants to produce large quantities of defensive compounds, such as terpenes, flavonoids, and alkaloids, which can decrease the palatability and nutritional quality of herbage to protect plants from further grazing and pest damage [23].

The plastic phenotypic response of an organism is mediated through the regulation of the transcriptome. In this process, gene expression is an intermediate molecular phenotype that links the genotype to environmental changes, while also linking diverse types of cells, tissues, and organs to express different phenotypes [24,25]. Gene expression changes in response to changing environmental conditions [i.e., gene expression plasticity (GEP)], are crucial for phenotypic plasticity and adaptive evolution [26,27]. For example, in Saccharomyces cerevisiae, altered levels of gene expression of many genes in the ergosterol biosynthesis pathway have been attributed to an adaptive lineage-specific response [28]. In a recent study of seven Drosophila species, $64 \%$ of the observed expression divergence was associated with adaptive changes driven by directional selection, and the adaptive gene expression was enriched in functional classes, including regulation, sensory perception, 
sexual behavior, and morphology [29]. Over shorter time frames, the modulation of gene expression has been found to be an effective regulator and indicator of the phenotypic status of organisms exposed to fluctuating environmental conditions. Examples of the latter include the response of Mytilus mussels to changing tidal conditions [30] and the plastic response of the fish Fundulus heteroclitus undergoing thermal acclimation [31].

Stipa grandis (Poaceae, $2 \mathrm{n}=44$ ) is a dominant species on the typical steppe of the Inner Mongolian Plateau, thus the responses of this species to over-grazing represent a major part of the ecosystem response to grazing disturbance in this region [32]. To date, several investigations have been conducted regarding this topic. These pioneering studies examined how grazing influences the succession and construction of the $S$. grandis community $[33,34]$, as well as the $S$. grandis biomass, functional traits, physiological ecology characteristics, population genetic diversity, and gene expression profiles $[35,36]$. Although studies evaluating responses to grazing suggested different populations of $S$. grandis exhibit phenotypic divergence to varying degrees, the transcriptome changes underlying such changes remain largely unknown. One study compared the transcriptomes of $S$. grandis under conditions of overgrazing and non-grazing [37]. This work has laid the foundation for our more detailed investigation of differential gene expression and grazing response of $S$. grandis. To better understand the phenotypic changes in $S$. grandis populations with different grazing conditions, we sequenced, assembled, and compared the transcriptomes of $S$. grandis under four grazing intensities. We identified gene expression dynamics and differentially expressed genes (DEGs) under different grazing treatments, and identified transcriptional regulation of genes closely associated with the Calvin-Benson cycle (CBC) and photorespiration. We herein elucidate the inferred divergent gene expression response of $S$. grandis under different grazing conditions. The present study develops our understanding of the adaptability of $S$. grandis to grazing and will facilitate the identification of the molecular mechanisms associated with their morphological and physiological changes of $S$. grandis under long-term grazing effects.

\section{Results}

\subsection{Sequencing Output and de novo Assembly}

Approximately 10 gigabase of clean data at the Q20 level (an error probability of 1\%) were obtained for each sample. The clean reads with the length of $100 \mathrm{bp}$ for all samples were de novo assembled into 67,705-115,918 unigenes, with a mean length and N50 value of 906-1373 bp and 1243-2078 bp, respectively (Table 1). To obtain the non-redundant and unextendable assemblies, the assembled unigenes of the 12 samples were further clustered into 251,412 all-unigenes, with an average length of $1854 \mathrm{bp}$ and an average N50 value of $2536 \mathrm{bp}$ (Table 1). Nearly $90 \%$ of the paired-end reads for each sample were mapped back to their own de novo assembled transcriptome (Table 1). A BUSCO analysis revealed that of 303 conserved sequences in the eukaryotic database, $68.7-94.1 \%$ complete and 3-23\% fragmented BUSCOs were identified in the assembled S. grandis transcriptomes (Table S1).

\subsection{Gene Quantification and Functional Annotation}

An analysis of the coefficient of variation (CV) indicated the expression of 33,241 all-unigenes in each grazing treatment was highly reproducible $(\mathrm{CV} \leq 0.5)$ (Table S2). Thus, these all-unigenes were retained for further analyses (results of the correlation analysis of the retained genes are presented in Figure S1). A BUSCO analysis of the filtered dataset showed that of the 303 orthologs, nearly $86.2 \%$ complete and $3.6 \%$ fragmented BUSCOs were identified (Table S1). The number of these all-unigenes with at least one sequence match based on a BLAST search of public databases was as follows: $31,029(93.35 \%)$ in the $\mathrm{Nr}$ database; 30,460 (91.63\%) in the NT database; 25,313 (76.15\%) in the Swiss-Prot database; $22,071(66.40 \%)$ in the GO database; $26,133(78.62 \%)$ in the KOG database; and 26,583 (79.97\%) in the KEGG database (Table S3). Overall, the top five species with BLAST hits to annotated unigenes were Brachypodium distachyon (39.47\%), Aegilops tauschii (16.65\%), Oryza sativa (6.72\%), Hordeum vulgare (6.69\%), and Oryza brachyantha (3.47\%). The GO annotation 
results indicated that in the three major GO categories, biological process, cell component, and molecular function, 'cellular process' (11,620;35\%), 'cell' (13,537; 40.7\%), and 'binding' $(11,381 ; 34 \%)$ were the dominant categories (Figure S2). Many of the identified transcripts were classified in the 'biological process' and 'cell component' categories, whereas only a few genes belonged to the 'molecular function' category (Figure S2). The KEGG pathway analysis indicated that the most enriched pathways were 'global and overview maps' (5223; $15.7 \%)$, 'translation' (2678; 8.1\%), 'signal transduction' (1277; 3.8\%), and 'transport and catabolism' (1397; 4.2\%) (Figure S3).

Table 1. Summary of sequencing and assembly results.

\begin{tabular}{ccccccccc}
\hline Sample & RR (M) & CR (M) & GCC (\%) & Q20 (\%) & AU (No.) & ML (bp) & N50 (bp) & TMR (\%) \\
\hline CK_1 & 106.66 & 101.80 & 47.79 & 97.73 & 101,788 & 1373 & 2078 \\
CK_2 & 105.80 & 101.64 & 47.57 & 97.59 & 101,392 & 1322 & 1953 \\
CK_3 & 104.76 & 100.89 & 47.81 & 97.83 & 89,023 & 1363 & 2030 \\
LG_1 & 105.96 & 102.07 & 47.62 & 97.72 & 108,636 & 1300 & 1890 \\
LG_2 & 107.36 & 102.71 & 47.92 & 98.03 & 113,212 & 1327 & 1956 \\
LG_3 & 105.71 & 101.88 & 47.95 & 97.78 & 115,918 & 1373 & 2052 \\
MG_1 & 107.08 & 102.77 & 47.42 & 98.12 & 67,705 & 906 & 1243 \\
MG_2 & 107.54 & 101.84 & 47.51 & 97.75 & 103,648 & 1304 & 1917 \\
MG_3 & 105.94 & 101.38 & 47.51 & 97.94 & 107,998 & 1304 & 1919 \\
HG_1 & 105.73 & 101.37 & 47.37 & 97.89 & 70,978 & 1144 & 1636 \\
HG_2 & 106.00 & 102.09 & 47.00 & 98.20 & 88,736 & 1239 & 91.75 \\
HG_3 & 106.01 & 102.90 & 47.07 & 98.43 & 90,147 & 1138 & 91.19 \\
All- & - & - & 47.27 & - & 251,412 & 1854 & 1644 \\
Unigene & & & & & & 93.49 & 92.09 \\
\hline
\end{tabular}

RR and CR denote raw read and clean read, respectively. M represents million. GCC represents GC content. Q20 means the percentage of bases with a Phred value $>20$. AU represents the number of assembled unigenes. ML indicates the mean length of the assembled sequences. N50 represents $50 \%$ of the assembled bases that were incorporated into sequences with length of N50 or longer. TMR indicates total mapped clean reads to an assembled transcriptome.

\subsection{Identification and Clustering of Differentially Expressed Genes}

Among the 33,241 all-unigenes, a total of 20,173 transcripts showed significant differential expression (FDR $\leq 0.001$ and the absolute value of $\log _{2}$ Ratio $\geq 1$ ) in pairwise comparisons of the four grazing intensities (highlighted in bold in Table S2). There were 5885 DEGs in CK vs. LG; 6914 in CK vs. MG; 8841 in CK vs. HG; 3947 in LG vs. MG; 14,850 in LG vs. HG; and 9564 in MG vs. HG. Of these DEGs, 2357 had a mean FPKM value greater than 10.0 across all samples (Table S4) and were retained for further analysis. More specifically, the number of the DEGs in each comparison was as follows: 736 DEGs in CK vs. LG; 979 in CK vs. MG; 800 in CK vs. HG; 307 in LG vs. MG; 1674 in LG vs. HG; and 1176 in MG vs. HG. The K-means clustering analysis assigned the above DEGs to 12 transcriptional clusters (Figure 1A and Table S5), with more than 200 DEGs in clusters 1, $2,7,9$, and 12. The KEGG pathway enrichment analysis revealed that many of the DEGs in clusters 1, 3, 4, 5, 6, 10, and 11 were associated with photosynthesis-related metabolic pathways. These pathways included 'photosynthesis', 'carbon fixation in photosynthetic organisms', 'carbon metabolism', 'porphyrin and chlorophyll metabolism', 'photosynthesisantenna proteins', and 'glyoxylate and dicarboxylate metabolism' (Figure 1B). For the GO enrichment analysis, the relatively predominant GO terms included organelle (chloroplast, ribosome, mitochondrial, etc.) organization, response to stimuli (heat and light), and cellular processes (translation, protein folding, gene silencing, etc.) (Figure 1C). 
A

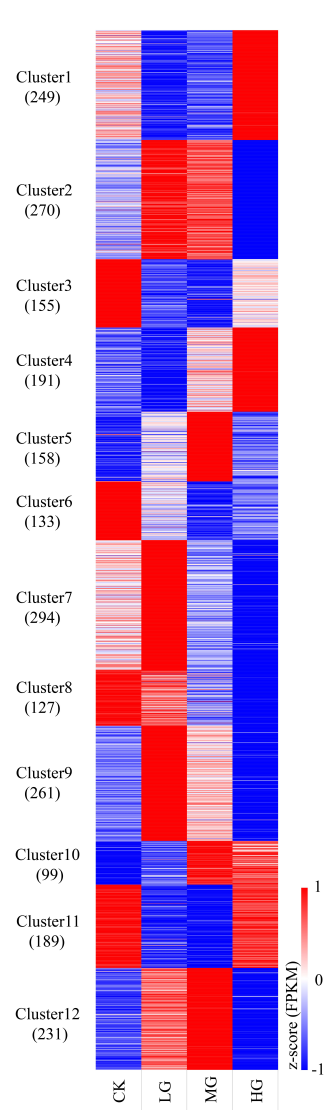

B

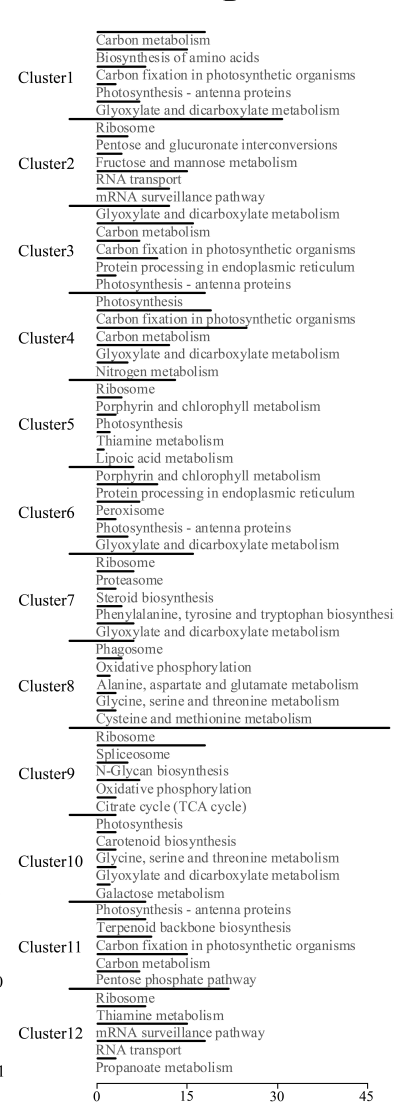

C

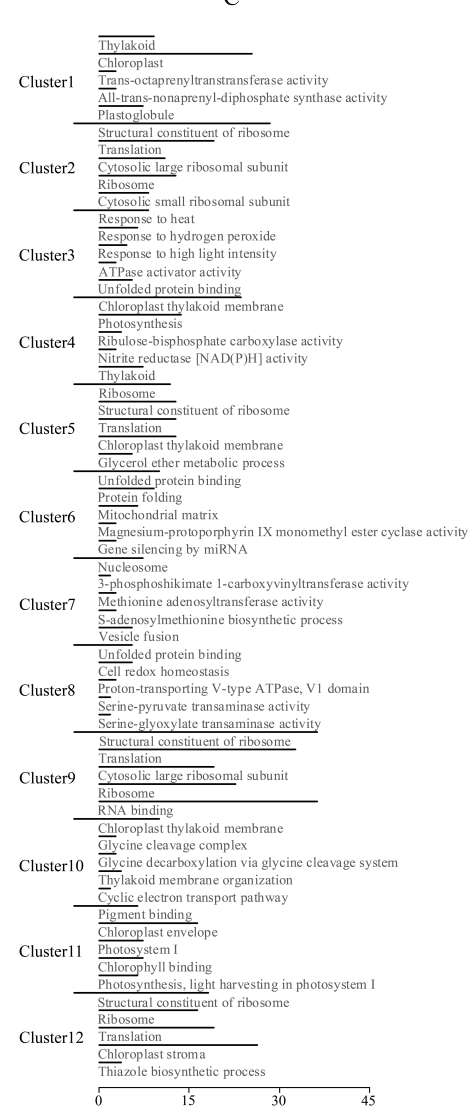

Figure 1. Expression patterns and functional annotations of the differentially expressed genes (DEGs). (A) K-means clustering of DEGs. The red-to-blue gradient indicates high-to-low expression levels. Prior to clustering, the expression level for each transcript over the four grazing treatments was standardized using z-scores. (B) KEGG pathway enrichment analysis. (C) GO enrichment analysis. In panels B and C, only the top five enriched GO terms and KEGG pathways are shown, respectively; the $x$-axis indicates the number of the unigenes, and clusters are separated by left-extended short black bars.

\subsection{Differentially Expressed Genes Related to the Calvin-Benson Cycle}

Among the analyzed transcripts, 114 transcripts encoded 11 enzymes involved in the CBC, and 38 were DEGs identified by the paired comparisons of the four grazing intensities (Table S6). The DEGs were divided into two categories based on their expression profiles (Figure 2). One group included the DEGs encoding ribulose-1,5-bisphosphate carboxylase/oxygenases (Rubiscos), 3-phosphoglycerate kinases (PGKases), glyceraldehyde-3phosphate dehydrogenases (GAPDHases), transketolases (Tkases), and ribose-phosphate isomerases (RPIases), and the gene expression levels varied slightly from CK to LG but were up-regulated significantly in response to grazing pressure (MG to HG). The other group comprised DEGs encoding fructose-1,6-bisphosphate aldolases (ALDases), sedoheptulose1,7-bisphosphatases (SBPases), phosphoribulokinases (PRKases), and ribulose-phosphate epimerases (RPEases). The expression levels of these transcripts were significantly downregulated from $C K$ to $L G$, relatively stable from $L G$ to $M G$, and then sharply up-regulated from MG to HG. Additionally, the expression levels of the unigenes encoding ALDases, PRKases, and RPEases under CK and HG conditions were almost the same (except for Unigene48588 and CL16574.Contig28). Among these DEGs, those that were highly expressed, with mean FPKM values greater than 100.0 across all samples (Table S6), encoded the following: four Rubiscos, two PGKases, four GAPDHases, five ALDases, one fructose1,6-bisphosphatase (FBPase), one TKase, one SBPase, one RPEase, one RPIase, one PRKase, and one Rubisco activase (RCA) (Figure 2). The expression profiles revealed significant 
changes for several transcripts in the $\mathrm{CBC}$ in response to grazing (Figure 2). Among the PGKase-encoding unigenes, the CL3380.Contig6 and CL3380.Contig10 expression levels were up-regulated nearly 2.4-times from LG (141.49 and 75.71, respectively) to HG (339.03 and 184.49, respectively). Regarding the GAPDHases, Unigene64285 expression was upregulated significantly from LG (141.73) to HG (356.98). For the RPIases, CL843.Contig1 and CL843. Contig10 were similarly expressed from CK to LG but exhibited the opposite expression trend from LG to HG. Among the ALDases, Unigene48588 and Unigene48595 expression levels changed by as much as 9.08 -times (1099.92 vs. 121.14) and 5.29-times (1500.74 vs. 283.65), respectively. The expression of the RCA unigene (Unigene11360) was sharply down-regulated by approximately 27 -times following the grazing treatments, reflecting the apparent negative regulation of this unigene (Figure 2).

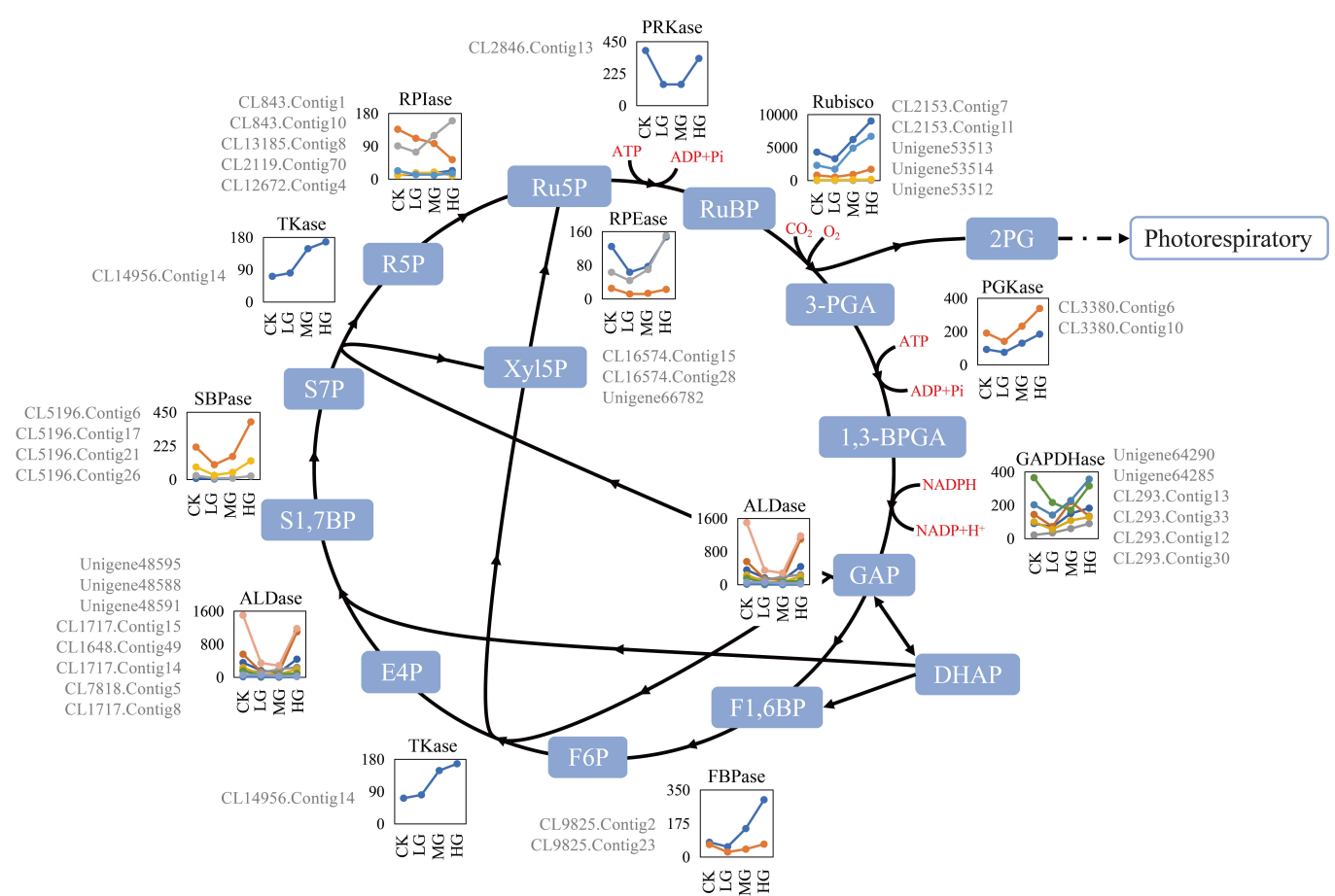

Figure 2. Expression patterns of differentially expressed genes (DEGs) in the Calvin-Benson cycle (CBC). The line and symbol chart next to each enzyme represents the expression profiles of DEGs shown in Table S6. The lines with different colors represent the assembled transcripts for an enzyme in the $\mathrm{CBC}$. According to the gene expression levels under $\mathrm{CK}$ conditions, these transcripts were listed next to each chart in descending order. The grazing gradient is shown on the $x$-axis, and the gene expression level (the mean FPKM value of three biological replicates) is shown on the $y$-axis. The carboxylation reaction catalyzed by Rubisco fixes $\mathrm{CO}_{2}$ into the acceptor molecule RuBP, forming 3-PGA. The reductive phase of the cycle follows with two reactions catalyzed by PGKase and GAPDHase, producing GAP. The GAP enters the regenerative phase catalyzed by ALDase and either FBPase or SBPase, producing F6P (fructose-6-phosphate) and S7P (sedoheptulose-7-phosphate). The F6P and S7P are then used in reactions catalyzed by TKase, RPIase, and RPEase, producing Ru5P (ribulose 5-phosphate). The final step, which is catalyzed by PRKase, converts Ru5P to RuBP. Rubisco is the initiating enzyme for the Calvin-Benson cycle and the photorespiratory cycle, fixing $\mathrm{O}_{2}$ into the acceptor molecule RuBP to form 2-PG, which is then metabolized via the photorespiratory pathway.

\subsection{Differentially Expressed Genes Related to Photorespiration}

A total of 127 all-unigenes and 38 DEGs were identified, encoding 12 enzymes related to the photorespiratory pathway (Table S7). The expression levels of the DEGs encoding one 2-phosphoglycolate phosphatase (PGLPase) (Unigene4982), five catalases (CATases) (Unigene20659, Unigene17925, Unigene11709, Unigene15777, and CL8442.Contig9), two serine hydroxymethyltransferases (SHMTases) (CL3053.Contig39 and CL3053.Contig41), 
three glycolate oxidases (GOXases) (CL95.Contig34, Unigene9650, and CL95.Contig47), and two glycine decarboxylases (GDCases) (CL1834.Contig3 and CL1834.Contig22) were downregulated from CK to LG, after which they were relatively steady before being up-regulated from MG to HG (Figure 3). The expression levels of the glutamine synthetases (GSases) (CL3536.Contig26), aminomethyltransferases (AMTases), glutamate: glyoxylate aminotransferases (GGTases), and hydroxypyruvate reductases (HPRases) unigenes were downregulated from CK to LG and then gradually up-regulated from LG to HG (Figure 3). The GOXase (Unigene9650), dihydrolipoamide dehydrogenases (DIDases) (CL12727.Contig15), and serine: glyoxylate aminotransferases (SGTases) (CL593.Contig32) expression levels were gradually up-regulated from $\mathrm{CK}$ to $\mathrm{MG}$ and then sharply down-regulated from MG to HG (Figure 3). Regarding the GOXase unigene (CL14974.Contig19) and five CATase unigenes (CL10067.Contig2, CL10067.Contig4, CL8442.Contig1, CL10067.Contig 5, and CL8442.Contig4), their expression levels were up-regulated from CK to LG, after which they changed slightly from LG to MG and decreased from MG to HG (Figure 3). The expression levels of the unigenes encoding SHMTase (Unigene49346) and SGTase (CL593.Contig33) were generally down-regulated from CK to HG (Figure 3). The DEGs for one PGLPase, two GOXases, one GGTase, two SGTases, and two SHMTases were relatively highly expressed, with mean FPKM values exceeding 100.0 across all samples (Table S7). Additionally, Unigene4982 (PGLPase) expression was up-regulated nearly 3-times from LG (84.81) to HG (253.03) (Table S7). Unigene9650 (GOXase) was highly expressed, with a MG expression level (443.96) that was about 3-times higher than the CK expression level (143.59) (Table S7). The expression of the SHMTase-encoding unigenes (CL3053.Contig39 and CL3053.Contig41) changed by as much as 3.43-times (326.94 vs. 95.39) and 2.15-times (595.44 vs. 276.86), respectively (Table S7). Among SGTase unigenes, the CL593.Contig1 and CL593.Contig32 expression level changes were similar from MG to HG, but the opposite expression trend was detected from CK to LG (Figure 3). 


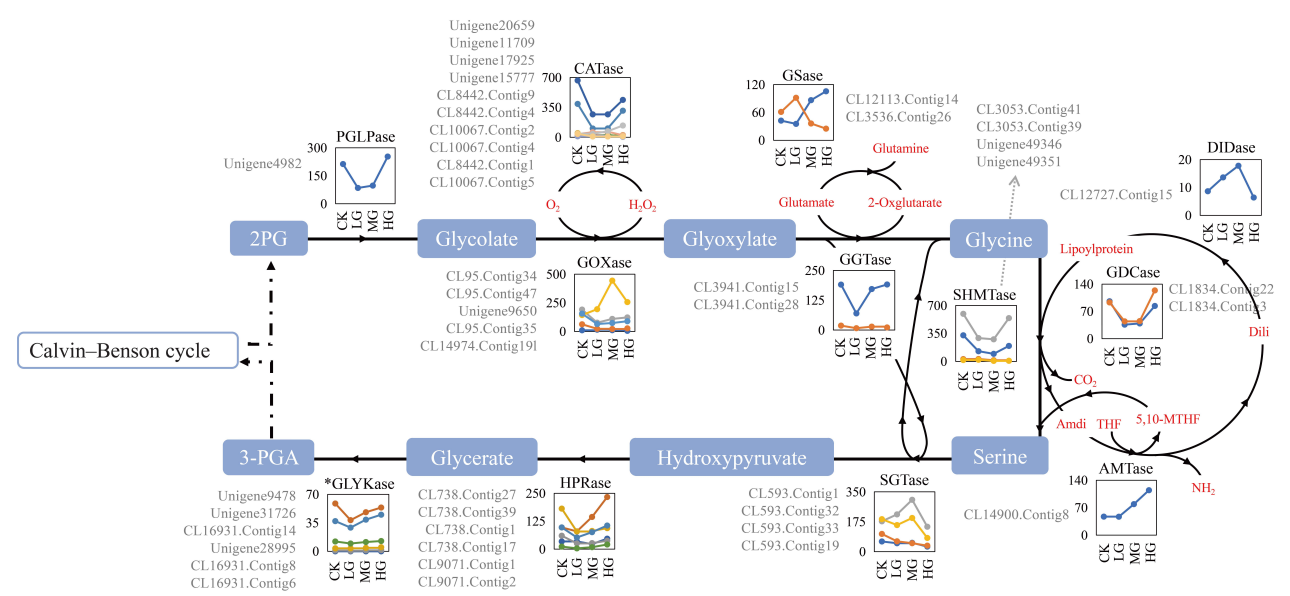

Figure 3. Expression patterns of differentially expressed genes (DEGs) in the photorespiratory pathway. The line and symbol chart next to each enzyme represents the expression profiles of DEGs shown in Table S7. The lines with different colors represent the assembled transcripts for an enzyme in the photorespiratory pathway. According to the gene expression levels under CK conditions, these transcripts were listed next to each chart in descending order. The grazing gradient is shown on the $\mathrm{x}$-axis and the gene expression level (the mean FPKM value of three biological replicates) is shown on the $y$-axis. The photorespiratory cycle is a process in photosynthetic cells involving the chloroplasts, peroxisomes, mitochondria, and the cytosol. In chloroplasts, Rubisco catalyzes the oxygenation of RuBP, which generates one molecule of 3-PGA and one molecule of 2-PG. The 2-PG is first dephosphorylated to glycolate by PGLPase, after which it diffuses into the peroxisome. In the peroxisome, the $\mathrm{O}_{2}$-dependent glycolate is oxidized to glyoxylate by GOXase to produce $\mathrm{H}_{2} \mathrm{O}_{2}$, which is quickly detoxified by CATase. Glyoxylate is transaminated to glycine by the parallel action of GGTase or SGTase. Glycine then moves into the mitochondrion, wherein the GDCase multienzyme system and SHMTase convert two molecules of glycine to one molecule of serine, $\mathrm{NH}_{3}$, and $\mathrm{CO}_{2}$. After being transported from the mitochondrion to the peroxisome, serine is converted by SGTase to hydroxypyruvate, which is reduced to glycerate by HPRase. The glycerate returns to the chloroplast to be phosphorylated by GLYKase (glycerate 3-kinase), and the resulting 3-PGA is converted to RuBP in the Calvin-Benson cycle. * represents transcripts that were not DEGs among the four grazing treatments.

\subsection{Experimental Validation}

To validate the gene expression plasticity, nine genes that were differentially expressed under the four grazing intensities were selected for qRT-PCR analysis. These analyses confirmed similar trends in expression patterns identified by RNA-seq for all genes under the various grazing conditions, although there were differences in the expression of these genes between 2018 and 2019 (Figure 4). 

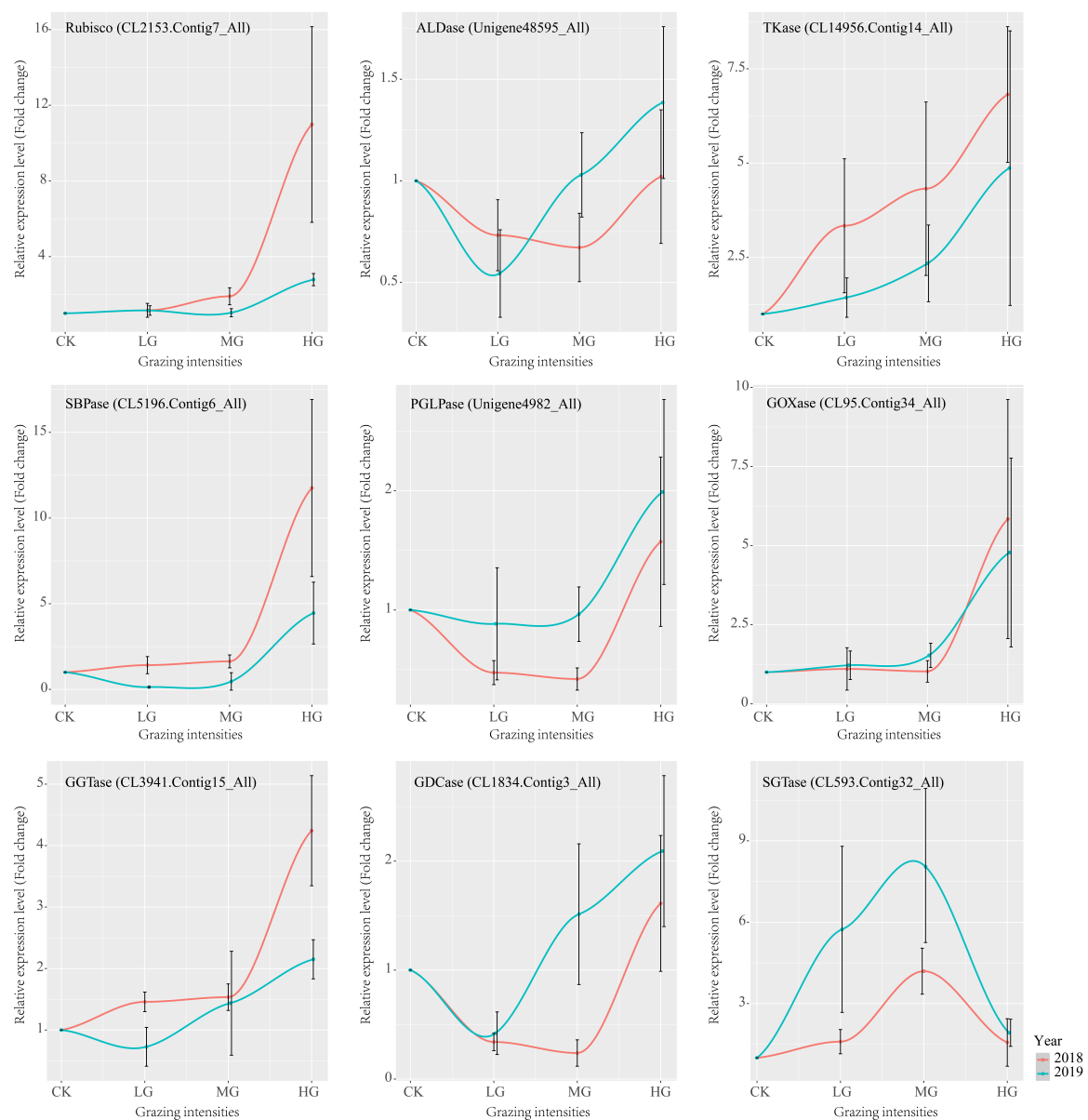

Figure 4. Expression patterns of selected genes measured using qRT-PCR. Nine genes were selected for validating observations of gene expression plasticity in various grazing intensities in two years of S. grandis samples. The $\mathrm{x}$-axis represents four different grazing intensities, and the $y$-axis indicates fold change of genes' relative expression levels. The color curves represent the gene expression patterns of the selected genes in 2018 and 2019, respectively. The error bars represent mean standard deviations $( \pm \mathrm{SD})$ of three biological replicates.

\section{Discussion}

\subsection{Gene Expression Plasticity Dataset for Stipa grandis under Different Grazing Intensities}

Under grazing conditions, plants generally exhibit two phases of response: an initial stress response that occurs within a few days after herbivore foraging and a regrowth response that occurs for several weeks following grazing [5]. One study identified that genes related to stress responses in wounded S. grandis, including wound, drought, and plant immunity, responded significantly over 12 hours compared with non-grazed $S$. grandis [37]. Another found that genes involved in the cellular-antioxidant, apoptotic, and amino acid metabolism pathways of Leymus chinensis responded to grazing within a 24 hours period [38]. In the present study, to explore the gene expression patterns of the regrowth stage in $S$. grandis in response to various long-term grazing intensities, we collected plant samples two weeks after grazing from the experimental grazing fields and analyzed the effects of the grazing intensities on the $S$. grandis transcriptome. Due to gene expression being substantially affected by fluctuations under the environmental conditions, the following strategies were adopted to minimize the influence of an open environment on gene expression and to obtain an accurate transcriptomic dataset for our study.

First, we applied rigorous sampling practices. Grazing reportedly affects photosynthes is-related pathways, which are characterized by obvious dynamic diurnal changes [39]. Accordingly, we strictly controlled the sampling time, with all samples collected between 9:00 am and 11:00 am. Under light conditions, the genes encoding many key enzymes 
are abundantly expressed in plants. These enzymes have important roles related to the regulation of photosynthetic activities in diverse plant species $[40,41]$. For example, Rubisco constitutes $30-50 \%$ of the soluble proteins in $C_{3}$ plant leaves [42]. Consistent with this expectation, Rubisco unigenes (CL2153.Contig7, CL2153.Contig1, and Unigene53513) were highly expressed in our field samples, with mean FPKM values of 3543.93 across the grazing intensities (Table S6).

We sequenced with high coverage three biological replicates for each grazing intensity. According to several quality assessment parameters of the assembled transcripts (i.e., number, average length, and N50), the mapping rate of clean reads of each sample to their assembled transcriptome (Table 1), and the BUSCO analysis (Table S1), we can infer that the transcriptional sequences obtained were of high quality, integrity and validity, indicating our sample collection method was suitable for the complex environment in the field.

Third, we applied multiple data filtering levels. Although an informative transcriptome dataset was constructed, several factors (e.g., variable splicing, incomplete assembly, tandem variations, and assembly bias) caused the merged transcriptome to contain an unusual number of transcripts. However, by filtering out the unigenes identified as not reproducibly expressed based on the coefficient of variation, a rational number $(33,241)$ of unigenes was retained for subsequent analyses. This process not only significantly decreased the sample bias resulting from the assembly method, it also ensured the comprehensive coverage of the $S$. grandis transcriptome. Gene annotations are considered useful for assessing the accuracy of the transcript sequences assembled from short-read data [43]. Among the analyzed transcripts, 93.42\% were annotated based on at least one of the screened public databases, and these transcripts were matched with a high probability score with homologs from model species, including Brachypodium distachyon, Aegilops tauschii, Oryza sativa, and Hordeum vulgare. This suggests that the $S$. grandis transcriptome in the present study was assembled and annotated correctly and that the unannotated transcripts probably represent genetic information unique to $S$. grandis. Our analyses indicated that 20,173 genes were differentially expressed across four grazing intensities. This number of DEGs was much higher than previously reported in a comparison of grazed and non-grazed pastures of $S$. grandis, wherein 13,221 DEGs were identified among 94,674 transcripts [37]. A lower number of DEGs were found in a comparison of over-grazed and non-grazed pastures of L. chinensis: 3341 DEGs identified in 116,356 unigenes [38], and an even lower number of DEGs were found in a comparison of ungrazed and grazed populations of Stipa breviflora: 686 DEGs obtained from 111,018 unigenes [44]. While the number of DEGs identified will be influenced by the analysis pipelines and filtering parameters used (please see comment below on DEGseq), the difference in the relative number of DEGs may also be explained by the greater environmental gradient across our four grazing conditions (Figure 5). Consistent with this interpretation, most DEGs identified in pairwise comparisons were inferred under the most contrasting environmental conditions: LG vs. HG (14,850 DEGs identified), followed by MG vs. HG (9564 DEGs identified), CK vs. HG (8841 DEGs identified), etc. To identify the most representative transcripts responding to grazing effects in S. grandis, an FPKM value greater than 10.0 across all samples was used as a threshold to further filter the overall identified DEGs. Accordingly, 2357 DEGs were identified, with functions suggesting they may have major roles related to basic metabolic activities and grazing responses in S. grandis (Figure 1B,C, Table S4). Several GO terms (e.g., catalytic activity, metabolic process, and cell part) and KEGG pathways (e.g., ribosome, glyoxylate and dicarboxylate metabolism, carbon metabolism, photosynthesis, and carbon fixation in photosynthetic organisms) were enriched among these unigenes. This information provides some insight into the cryptic physiological, plastic and adaptive responses of $S$. grandis to recover under varying levels of grazing stress. Similar to the response of one-week grazed alfalfa (Medicago sativa) [45], patterns of differential expression of $S$. grandis suggested that carbon assimilation, ribosome organization, response to stimuli, and translation were at a more functional level following the recovery period after grazing. In contrast, cellular processes and metabolic pathways including secondary metabolite 
production, hormone signaling, and wound response, etc., were relatively inactive in $S$. grandis. This suggests that while the regulation of gene expression in response to grazing shows some differences between species, the regulation of photosynthesis may exhibit a common response to grazing pressures (Figure 1).

Lastly, potential shortcomings of the present study need to be mentioned. Gene quantification and differential expression analyses were performed using FPKM normalization and the R package DEGseq. Alternative methods that include normalization for both library size and transcriptome gene composition have been found to be much more effective than DEGseq in distinguishing true and false positives (e.g., DESeq2 and edgeR) [46-48]. However, when the number of biological replicates is small, such as in our study, DEGseq has also been found to produce far fewer false negatives than DESeq2 and edgeR [46]. This may have helped our study in which we had a small number of biological replicates for analysis. We found that gene and pathway enrichment on the initial set of differentially expressed candidate genes identified by DEGseq was effective in identifying true positives that were subsequently validated using qRT-PCR. The genetic differentiation of populations can also lead to false positives and misleading inferences of differential expression [49]. This was also not accounted for in our study. The impact of false positives and false negatives on downstream ontology inferences is an important issue for biologists that requires further study.

\subsection{The Expression Patterns of Genes Related to the Calvin-Benson Cycle in Stipa grandis Were Changed under Different Grazing Intensities}

Photosynthesis is a sensitive indicator of grazing stress in various grassland plants. The CBC is the initial pathway for photosynthetic carbon fixation, and changes to the expression of genes encoding the associated enzymes reportedly influence the growth of higher plants $[40,50]$. In the current study, grazing-induced transcriptional changes were detected for 114 unigenes encoding 12 enzymes involved in the CBC (Figure 2 and Table S6), suggesting that various grazing conditions altered the expression patterns of these CBC-related unigenes.

The expression levels of CBC-related genes were compared in S. grandis between grazed plots (LG, MG, and $\mathrm{HG}$ ) and non-grazing (CK) conditions, wherein the vegetation represents the top-level community [51,52]. Important to note is that herbivory is a form of predation in which animals draw off for their own use, energy and nutrients from the plants they graze, and that grasses in general are adapted to herbivory as a feature of their natural environment. Previous studies have shown that, with increased grazing intensity, the exposed soil surface area of plots increases, the canopy height of the plant community decreases, and the existing aboveground biomass (including the litter) decreases (Figure 5) [53]. It follows logically that a gradient of defoliation intensity such as in this experiment, also introduces a gradient of biomass removal intensity that will have impact on both the energy status and nutrient status of the plant. In the temperate sward forming forage grass Lolium perenne, carbohydrate levels fall rapidly after defoliation and recover gradually over approximately two weeks [54], while a phenomenon known as shoot size-density compensation comes into play such that a higher density of smaller shoots will help in the restoration of lost leaf area under more severe defoliation. In very severe defoliation, new shoots do not appear, likely because of substrate limitations [12]. More complex processes come into play in determining grazing effects on tussock-forming grasses [13], of which S. grandis is an example (Figure 5); however, it would be expected that more intense defoliation would impose greater substrate limitations in tussock-forming grasses like S. grandis, as in the sward-forming grasses. This principle of progressively reducing plant substrate status with increasing grazing intensity thus provides one framework against which to understand the photosynthesis responses observed in the present experiment. While the $\mathrm{CBC}$ performed similarly under non-grazing $(\mathrm{CK})$ and heavy grazing (HG) conditions, the expression levels of CBC genes relevant for $S$. grandis growth and survival varied considerably between CK and HG. Specifically, the HG treatment induced the up-regulated expression of several unigenes encoding CBC enzymes. We 
propose that this response may be part of an adaptive strategy and plastic response that enables substrate-depleted or damaged plants to use their limited photosynthetic units to reconstruct organs and to maintain an appropriate balance in the materials and energy metabolism in the above- and below-ground plant parts $[19,55]$.

This suggestion is consistent with a grazing optimization hypothesis that states that the unaffected biomass and small stature of plants under grazing stress reflect the promotion of net primary production [56]. Increased photosynthetic rate is a mechanism that has been suggested to support this hypothesis [57]. Furthermore, studies on the Inner Mongolia steppe have revealed that under frequent grazing stress, $S$. grandis plants exhibit dwarfism and induce efficient compensatory photosynthetic activities that can promote leaf regeneration and resistance to severe grazing $[5,36]$. This regenerative ability is crucial because $S$. grandis survival requires the rapid restoration of active photosynthesis and growth [58]. After grazing, the remaining or newly developed organs can undergo physiological changes that enhance photosynthesis, which can further increase the photosynthetic capacity of the grazed plants [55,59]. Under LG and MG conditions, when plant diversity is relatively high, livestock will selectively graze on the highly palatable vegetation, such as $L$. chinensis, Cleistogenes squarrosa, and Chenopodium glaucum, resulting in minimal damage to S. grandis [60]. Thus, the competition for resources decreases for S. grandis compared with the competition under CK conditions. The relatively abundant resources make it easier for S. grandis plants to maximize physiological growth under LG and MG conditions [5]. Therefore, it is unnecessary to invest as much material and energy in resource competition. In the present study, the expression levels of unigenes encoding Rubisco, SBPase, TKasse, and ALDase were down-regulated significantly under LG and MG conditions, which was consistent with the observed changes to photosynthetic-related physiology and phenotypic characteristics of $S$. grandis in response to grazing.

However, the above hypothesis of response to substrate depletion and herbivory damage does not explain the elevated levels of expression of CBC-related genes in the CK plot compared with those in the LG plot. In regions with a high plant density, vegetation with a large above-ground biomass, and rich biodiversity, competition is the main driving force of the community [61]. To gain a competitive advantage with limited resources in this situation, we propose $S$. grandis will increase its carbon fixation capacity to generate more resources. If this assumption is correct, we predict that key genes encoding CBC enzymes would be expected to be highly expressed to increase photosynthetic activity under conditions of increased competition.

Control over the rate of carbon fixation in the CBC is shared by a few enzymes. Analyses of antisense plants generated direct experimental evidence that expression-level changes to Rubisco, SBPase, ALDase, and TKase genes can influence the carbon flux through the CBC, with consequences for photosynthesis and growth [40]. In our study, of the identified unigenes in this cycle, 38 were defined as DEGs, and several Rubisco, SBPase, ALDase, TKase, and GAPDHase unigenes were highly expressed, with mean FPKM values greater than 100.0 (Table S6). These results suggest these enzymes have significant regulatory functions affecting the $\mathrm{CBC}$ during $S$. grandis responses to grazing.

Rubisco catalyzes the carboxylation of the $\mathrm{CO}_{2}$ acceptor molecule ribulose 1,5-bisphosp hate (RuBP) to initiate the CBC (Figure 2) [62]. This enzyme comprises eight large (rbcL) and eight small (rbcS) subunits [63], and its catalytic properties are determined by the large subunit encoded by the chloroplast genome [64]. In the current study, the five Rubisco DEGs were rbcS-encoding unigenes. Previous studies demonstrated that rbcS influences Rubisco catalytic efficiency, $\mathrm{CO}_{2}$ specificity, activity, quantity, assembly, and stability $[65,66]$. Moreover, $\mathrm{rbcS}$ and $\mathrm{rbcL}$ gene expression levels are positively correlated [67], and rbcS may function as a $\mathrm{CO}_{2}$ storage reservoir [68]. Thus, the highly expressed $S$. grandis rbcS unigenes (mean FPKM of 2156.42) identified in this study may indicate that regulating the Rubisco content is important for regulating the CBC in S. grandis as a response to differential grazing stresses. 
RCA is an $\mathrm{AAA}^{+}$ATPase that uses the energy from ATP hydrolysis to remove inhibitory sugars at the RCA site to generate a catalytically active enzyme with a temperature optimum below $40^{\circ} \mathrm{C}[69,70]$. In the present study, an RCA unigene (Unigene11360) was highly expressed under CK conditions (FPKM of 653.40), but with grazing, its expression was significantly down-regulated (Figure 2 and Table S6), indicative of its varying roles under the four grazing conditions. Under CK conditions, the abundant RCA can accelerate $\mathrm{CO}_{2}$ fixation, activate Rubisco and induce the expression of key genes in the CBC [70]. However, the microenvironment of plants survive grazing changes because of a decrease in humidity and increases in temperature, surface exposure, light radiation, and evaporation, which ultimately lead to unstable and inactive RCA [71,72]. Additionally, because RCA is a labile protein in vivo, the cost of accumulating RCA is quite high [73]. Therefore, in response to grazing, S. grandis does not actively synthesize RCA, and the carbon turnover in the $\mathrm{CBC}$ is mediated by other $\mathrm{CBC}$ enzymes to maintain photosynthesis and regeneration.

Highly efficient photosynthetic $\mathrm{CO}_{2}$ fixation depends not only on the carboxylation capacity of Rubisco but also on the regeneration of RuBP [74]. This regeneration is largely regulated by SBPase, TKase, and ALDase [74], which catalyze the irreversible reactions and induce the metabolic branches of the CBC [40]. The over-expression of ALDase and SBPase genes individually or together in tobacco and Arabidopsis thaliana significantly increases photosynthetic activities as well as the overall biomass and seed yield, especially under elevated $\mathrm{CO}_{2}$ conditions [50,75]. However, a small decrease in the plastid TKase activity can dramatically inhibit photosynthesis and growth in antisense tobacco and cucumber transformants [76,77]. In the current study, ALDase, SBPase, and TKase unigenes in the $S$. grandis $\mathrm{CBC}$ were highly and differentially expressed (Figure 2 and Table S6), suggesting that the transcriptional regulation and/or GEP of these enzymes may have important effects on RuBP regeneration, the photosynthetic capacity, and regrowth during S. grandis responses to grazing. Among these enzymes, ALDase and SBPase unigenes were similarly expressed (Figure 2 and Table S6), indicating that, when photosynthesis was relatively strong under $\mathrm{CK}$ and $\mathrm{HG}$ conditions, the branching reaction efficiency of the $\mathrm{CBC}$ increased significantly in S. grandis. Consequently, ALDase effectively catalyzed the conversion of dihydroxyacetone phosphate (DHAP) and glyceraldehyde-3-phosphate (GAP) to fructose1,6-bisphosphat (FBP) as well as the conversion of DHAP and erythrose 4-phosphate to sedoheptulose-1,7-bisphosphate (SBP) [78] (Figure 2), after which SBPase catalyzed the dephosphorylation of SBP to S7P (sedoheptulose-7-phosphate). These reactions can lead to the formation of a metabolic flux that enhances the carbon partitioning in the cycle and avoids the negative feedback regulation due to metabolic intermediates (e.g., glycolate and glyoxylate) $[79,80]$. Additionally, up-regulated ALDase and SBPase gene expression might further activate Rubisco by promoting the regeneration of RuBP in the CBC [50,81], thereby accelerating the carbon turnover to achieve compensatory photosynthesis and to stimulate the restorative growth of $S$. grandis plants. Interestingly, the expression of the TKase unigene (CL14956.Contig14) increased as the grazing intensity increased, with expression levels significantly higher than that under CK conditions. This suggests that the enzyme was actively engaged in regenerating RuPB in the grazed $S$. grandis plants and that it can effectively alleviate the limitation of RuBP to maintain photosynthesis under grazing stress. The significant up-regulation of TKase unigene expression might be highly related to the hyper-compensatory photosynthesis of $S$. grandis, especially under the LG and MG conditions.

\subsection{Gene Expression Plasticity Affecting the Photorespiration Is Important for Stipa grandis Adaptations to Grazing}

Plant photorespiration involves a complex network of enzymatic reactions and is linked to the $\mathrm{CBC}$ to form a photosynthetic photorespiratory super-cycle that is responsible for nearly all of the biological $\mathrm{CO}_{2}$ fixation on Earth [82]. Photorespiration begins with the oxygenation of RuBP by Rubisco, and the synthesized 2-phosphoglycolate (2-PG) causes a significant carbon loss and impedes carbon fixation as well as allocation [83]. Therefore, the 
degradation of 2-PG during photorespiration directly affects the overall carbon metabolism in plants [83].

The PGLPase enzyme catalyzes the formation of glycolate from 2-PG, and its activity is essential for plant carbon fixation and distribution. In this study, a PGLPase unigene (Unigene4982) was highly expressed in response to the CK and HG treatments, but its expression was significantly down-regulated under LG and MG conditions (Figure 3 and Table S7). A previous study indicated that PGLPase expression and the 2-PG content are inversely related [83]. Therefore, the 2-PG levels under the LG and MG conditions were higher than those under the CK and HG conditions, reflecting the differences in carbon fixation and allocation between these treatments. Enzymatic analyses have demonstrated that high 2-PG levels inhibit A. thaliana triose-phosphate isomerase (TPI) and SBPase [83], and SBPase further limits the carbon flux of the RuBP regeneration phase in the CBC [84]. In $S$. grandis, PGLPase unigene expression was consistent with SBPase unigene expression, indicating RuBP regeneration was negatively regulated by 2-PG under LG and MG conditions. In contrast, under CK and HG conditions, the CBC carbon flux leading to RuBP regeneration was probably attributed to the substantial metabolism of 2-PG. Under heavy grazing conditions, abiotic stressors, such as high light intensity, water scarcity, increased temperatures, and elevated $\mathrm{O}_{2}$ partial pressures, might promote the oxidation of RuBP to form 2-PG [85]. The relatively high PGLPase unigene expression level (FPKM of 253.03) under this condition suggests that the PGLPase activity was not correlated with the photorespiratory flux (2-PG hydrolysis), and an increase in PGLPase activity may be beneficial for $S$. grandis under HG conditions. Hence, PGLPase is not a limiting factor for the photorespiratory flux, but it prepares the cycle for a considerable influx of 2-PG due to abiotic stresses $[83,86]$ and enhances plant stress tolerance.

Another photorespiratory enzyme related to abiotic stress tolerance is GOXase, which catalyzes the conversion of glycolate to glyoxylate and produces $\mathrm{H}_{2} \mathrm{O}_{2}$. As a second messenger, $\mathrm{H}_{2} \mathrm{O}_{2}$ plays an important role in plant defense reactions [87]. Because it produces glyoxylate, GOXase represses Rubisco and RCA in rice and maize [88,89]. In S. grandis, the GOXase unigene (CL95.Contig34) expression pattern was similar to that of the RCA and Rubisco unigenes, reflecting the likely effect of GOXase on RCA and Rubisco. Nevertheless, under HG conditions, PGLPase and GOXase unigene expression levels were significantly up-regulated, which would have increased the tolerance of S. grandis to stressors due to grazing.

In the photorespiratory pathway, GGTase, SGTase, GDCase, and SHMTase form networks regulating glycine and serine (Figure 3). The plant cellular glycine: serine ratio is a sensitive indicator of photorespiratory activity [90]. The over-expression of GGTase genes can increase glycine and serine levels, whereas up-regulated SGTase gene expression has the opposite effect on serine levels [91]. These two reactions share common metabolites and exhibit a mutual decreasing trend (Figure 3). In this study, the unigenes encoding these two enzymes had the opposite expression patterns (GGTase: CL3941.Contig15; SGTase: CL593.Contig32), indicative of their roles in regulating the balance between glycine and serine contents in S. grandis under different grazing conditions. The GDCase gene expression level is reportedly a key determinant of photorespiratory flux control [92]. Remarkably, increases in GDCase activity facilitate carbon conversion throughout the photorespiratory cycle [93]. Simkin et al. [75] determined that plant growth and photosynthetic activities increase following the combined over-expression of GDC-H, SBPase, or ALDase genes. Therefore, the positive correlation between the photorespiration carbon flux and the CBC is one of the determinants of photosynthetic efficiency and biomass, indicating that adjusting the carbon flux via photorespiration to achieve compensatory photosynthesis is an important strategy adopted by $S$. grandis in response to differing grazing intensities. Here we construct a metabolic synthesis consistent with our data but not definitively proven by them, as a tentative understanding to allow the formulation of confirmatory hypotheses for testing in future research. 


\section{Materials and Methods}

\subsection{Study Site and Grazing Intensities}

The grazing experiment was performed at the eastern edge of Xilinhot, Inner Mongolia, China $\left(44^{\circ} 08^{\prime} 31^{\prime \prime} \mathrm{N}, 116^{\circ} 18^{\prime} 45^{\prime \prime} \mathrm{E}\right.$, Altitude $\left.1129 \mathrm{~m}\right)$, characterized as a semi-arid continental climate with very cold and dry winters but warm and humid summers [94]. The average annual temperature in this region is $0{ }^{\circ} \mathrm{C}-4^{\circ} \mathrm{C}$, and the average precipitation is less than $300 \mathrm{~mm}$. The rainfall is mostly concentrated in the June-September period (plant growth season stage). The soil type in this area is a 'chestnut soil' (i.e., calcic orthic Aridisol according to the US soil taxonomic system) [95], and the vegetation type is a typical steppe dominated by the perennial bunchgrass Stipa grandis and the perennial rhizomatous grass L. chinensis. Other companion species, such as C. squarrosa, Agropyron cristatum, and Carex korshinskyi, were also common in the study region. The grazing treatments were initiated in 2013. Specifically, 12 paddocks $(120 \mathrm{~m} \times 120 \mathrm{~m})$ were fenced off, and four different grazing intensities were established in a randomized complete block design with three replicates. The four grazing intensities were as follows: no grazing ( $\mathrm{CK}$, no sheep), light grazing (LG, 2 sheep $\cdot \mathrm{ha}^{-1}$ ), moderate grazing $\left(\mathrm{MG}, 4\right.$ sheep $\left.\cdot \mathrm{ha}^{-1}\right)$, and heavy grazing (HG, 8 sheep $\cdot$ ha $^{-1}$ ). For each grazing intensity, 28 Inner Mongolian Ujimqin sheep ( 3 years old, $60 \mathrm{~kg}$ body weight) were allowed to repeatedly graze for 3, 6 , and 12 days per month for the LG, MG, and HG treatments (one after the other in series), respectively, during the vegetation growing season (i.e., June-September) every year. The sheep were allowed to graze from 7 am to $6 \mathrm{pm}$ every day and were housed at night. They had free access to water and minerals.

\subsection{Sample Collection, RNA Extraction, and Transcriptome Sequencing}

In order to identify gene expression responses related to the compensatory photosynthesis behavior of $S$. grandis in the recovery growth stage after grazing, plant samples were collected from 9:00 am to 11:00 am on a sunny day at the end of July (two weeks after grazing). The steppe grasslands of this area have a net primary productivity in the region of 3-5 $\mathrm{t}$ dry matter (DM) ha ${ }^{-1} \mathrm{y}^{-1}$, with July being the time of peak herbage accumulation rate in the mid growing-season $[96,97]$. Figure 5 shows the vegetation status of the grazing plots when the samples were collected. Emerging and healthy leaves of $S$. grandis plants were collected. In each of the four grazing intensities, three biological replicates were sampled. All samples were immediately frozen in liquid nitrogen and stored at $-80{ }^{\circ} \mathrm{C}$ for the subsequent transcriptomic analysis. Total RNA was extracted from the frozen tissues with the TRIzol reagent (Invitrogen, Life Technologies Corporation, Carlsbad, CA, USA) according to the manufacturer's instructions. The extracted RNA was treated with deoxyribonuclease I ( $\mathrm{TaKaRa}$ Bio Inc., Otsu, Shiga, Japan) for $30 \mathrm{~min}$ at $37^{\circ} \mathrm{C}$ to remove residual DNA. The total RNA was quantified, and the quality was assessed using the Agilent 2100 Bioanalyzer (Agilent Technologies, Palo Alto, CA, USA), with a minimum RNA integrity number of 6.5. The poly (A) mRNA was isolated with Oligo (dT) Beads and then used for the construction of cDNA libraries. Briefly, the purified mRNA was fragmented. Then first-strand cDNA was generated using random hexamer-primed reverse transcription, followed by second-strand cDNA synthesis. Afterward, A-Tailing Mix and RNA Index Adapters were added following end repair. The above cDNA fragments were amplified by PCR and purified by Ampure XP Beads. Then, the double-stranded PCR products were denatured and circularized with the splint oligo sequence to obtain a single-strand circle DNA (ssCir DNA). The ssCir DNAs were amplified with phi29 polymerase to make DNA nanoballs (DNBs) and to obtain the library. Finally, the cDNA library for each sample was sequenced paired-end with the BGISEQ-500 platform by BGI Tech Solution Co., Ltd. (Wuhan, China). 

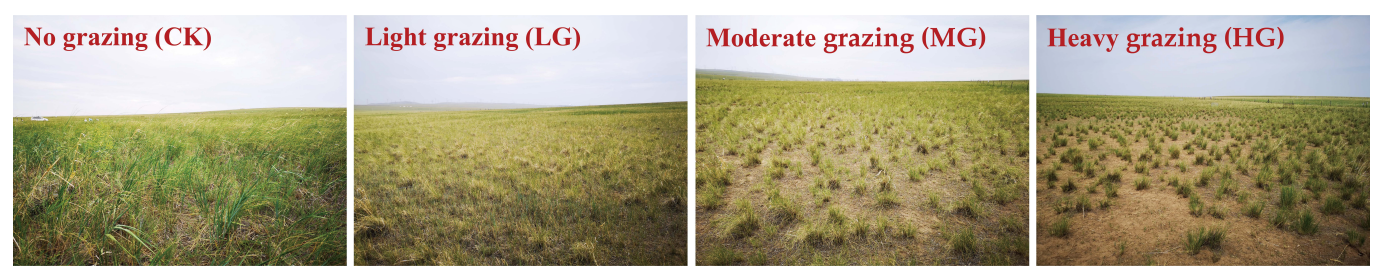

Figure 5. Vegetation status of plots of the four grazing intensity treatments (Photographed 28 July 2018).

\subsection{Data Filtering and de novo Assembly}

The raw sequence reads for all samples were filtered with Trimmomatic (version 0.36) [98] to remove adapter-contaminated reads, low-quality reads ( $>20 \%$ low-quality nucleotides), and reads with ambiguous nucleotides $(>5 \%$ ' $\mathrm{N}$ ') to obtain clean reads, which were counted with SOAPnuke (version 1.4.0) [99]. The clean reads of each sample were then de novo assembled into a transcriptome using Trinity (version 2.0.6) [100], with an optimized k-mer length (25-mer). The subsequent clustering and elimination of redundancies were completed with TGICL (version 2.1) [101] to obtain unigenes. The unigenes assembled for all samples were then clustered with TGICL to obtain the non-redundant and unextendable assemblies (i.e., all-unigenes). To assess the completeness of the assembled transcriptomes, a BUSCO analysis was performed based on 303 conserved sequences in the eukaryotic database [102] (http:/ / busco.ezlab.org/v2/datasets/eukaryota_odb9.tar.gz, accessed on 9 September 2018).

\subsection{Gene Expression Quantification and Functional Annotation}

Bowtie 2 (version 2.3.4.1) was used to map the reads of each sample to the merged transcriptome to quantify the expression level for each all-unigene in 12 samples [103]. The number of mapped reads was then estimated using RSEM (version 1.2.12) [104], with the default setting, for each sample. The normalized FPKM (fragments per kilobase of exon model per million mapped reads) values for each unigene in the 12 libraries were used to represent gene expression levels. To identify genes with reproducible expression levels in three biological replicates, we calculated the coefficient of variation (CV) for the gene expression of each grazing intensity. For each treatment, only genes with $C V \leq 0.5$ were retained for further analyses. The correlations between all pairs of samples were analyzed with the hierarchical clustering of Pearson's correlation coefficients based on the gene expression levels. Symmetrical heat maps were generated with ggplot2 (version 1.0.0) [105] within R version 3.0.2 (R Development Core Team, 2012). Next, a BUSCO analysis was performed to evaluate the completeness of the filtered transcripts.

To predict the probable functions of the retained all-unigenes, their sequences were aligned with the sequences in public databases with the BLASTX algorithm, with a significance threshold E-value $<10^{-5}$. The following databases were screened: non-redundant (Nr) protein database (http:/ / www.ncbi.nlm.nih.gov, accessed on 11 September 2018), the Swiss-Prot protein database (http:/ / www.expasy.ch/sprot, accessed on 16 September 2018), the Kyoto Encyclopedia of Genes and Genomes (KEGG) pathway database (http:/ / www.genome.jp/kegg, accessed on 16 September 2018), and the Cluster of Orthologous Groups (COG) database (http:/ / www.ncbi.nlm.nih.gov/COG, accessed on 16 September 2018). The Blast2GO software (version 2.5.0) [106] and the Gene Ontology (GO) database were used to functionally annotate unigenes and assign them to the main GO functional categories (molecular function, cellular component, and biological process).

\subsection{Identification of Differentially Expressed Genes (DEGs) and Analysis of Functional Enrichment}

To identify DEGs among the four grazing intensities in the above dataset, pairwise comparisons were performed using an R package DEGseq (http:/ / www.bioconductor. org/packages/release/bioc/html/DEGseq.html, accessed on 19 September 2018) [107]. The $\mathrm{p}$-values were adjusted for multiple testing using the Benjamini-Hochberg method 
to control the false discovery rate (FDR) [108] and with Storey and Tibshirani's statistical methods [109]. A FDR $\leq 0.001$ and $\mid \log _{2}$ (fold-change) $\mid \geq 1$ were used as the significance threshold to infer gene expression differences. To identify the most representative transcripts that might have played roles in response to grazing in S. grandis, we only considered DEGs that had mean FPKM values greater than 10.0 in all samples for further analysis. It is worth noting that this criterion might filter out a number of transcripts that were shut off or turned on in response to grazing stress because samples where these transcripts were not expressed might pull the mean FPKM under 10.0. To evaluate the expression patterns of the identified DEGs for the four grazing intensities, a K-means clustering analysis was performed by using the MeV software (version 4.9) [110]. The DEGs for each cluster were then subjected to GO and KEGG Ontology enrichment analyses by using MapMan (version 3.6.0) [111].

\subsection{Experimental Validation of the Gene Expression Plasticity}

Stipa grandis samples were collected for two consecutive years (2018 and 2019) from the plots mentioned in 4.2 for qRT-PCR analysis. Total RNA was isolated from the samples using RNAzol reagent (Genbetter, Beijing, China) according to the manufacturer's instructions. The integrity and purity of the RNA samples were determined by $1 \%$ agarose gel electrophoresis and NanoDrop 2000 spectrophotometer (Thermo Fisher Scientific, Waltham, MA, USA). Subsequently, 1 ug total RNA was reverse transcribed into cDNA using a PrimeScript RT Reagent Kit with genomic DNA (gDNA) Eraser (TaKaRa, Dalian, China) according to the manual instructions. Nine unigenes in the Calvin-Benson cycle and photorespiration pathway were selected for qRT-PCR validation, including CL2153.Cotig7, Unigene48595, CL14956.Contig14, CL5196.Contig6, Unigene4982, CL95.Cotig34, CL3941.Contig15, CL1834.Conig3, and CL593.Contig32. Primers were designed using the NCBI Primer-Blast program (https:/ / www.ncbi.nlm.nih.gov/ tools / primer-blast/, accessed on 18 January 2021), and the primer sequences are shown in Table S8. Sgactin-7 was used as the internal reference gene [112]. qRT-PCR was carried out on a Eco real time PCR platform (Illumina, San Diego, CA, USA) using a SYBR-Green real-time PCR mix (TaKaRa, Dalian, China). Reactions were performed in a $20 \mathrm{ul}$ final volume, which contained $100 \mathrm{ng}$ of cDNA template, $0.8 \mathrm{ul}(0.4 \mathrm{um})$ each of forward and reverse primers, $10 \mathrm{ul}$ of SYBR Premix Ex Taq II, $0.4 \mathrm{ul}$ of ROX Reference Dye or Dye II, and $6 \mathrm{ul}$ of sterile distilled water. The thermal cycling programs were as follows: first denaturation $95^{\circ} \mathrm{C}$ for $30 \mathrm{~s}$, then 40 cycles of denaturation at $95^{\circ} \mathrm{C}$ for $5 \mathrm{~s}$, annealing and extension at $60^{\circ} \mathrm{C}$ for $34 \mathrm{~s}$. All reactions were performed on three technical replicates across the nine unigenes. The relative expression levels of the investigated genes were normalized to Sgactin-7 and calculated using the $2^{-\Delta \Delta \mathrm{Ct}}$ method.

\section{Conclusions}

Comparative transcriptomic analyses revealed that the gene expression of $S$. grandis has plasticity induced by long-term differential grazing intensities, which involves altered regulation of many biological processes and metabolic pathways. The similar expression profiles of genes related to the $\mathrm{CBC}$ and photorespiration pathways suggest that these pathways synergistically respond to grazing to promote recovery growth and stress tolerance in S. grandis. Our findings provide novel insights into the grazing responses of $S$. grandis on the gene expressional level and will facilitate future investigations of the relevant regulatory roles and mechanisms of genes underlying the plastic response of grassland plant species to grazing.

Supplementary Materials: The following are available online at https:/ /www.mdpi.com/article/10 $.3390 /$ ijms222111882/s1.

Author Contributions: Project design, Z.D.; sampling, Z.D., Y.J., L.H., J.L. and Y.Z.; wet lab work, Y.T. and Y.J.; data submission, Y.T.; bioinformatics analyses, data analysis, writing, and review, Z.D., 
Y.J., Y.T., P.J.L., C.M. and F.Y.L.; Grazing experimental design, C.L. All authors have read and agreed to the published version of the manuscript.

Funding: This research was funded by the National Natural Science Foundation of China (31860078), the National Key Research and Development Program of China (2016YFC0500501), the New Zealand Marsden Fund (MAU1707) and the Open Project Program of Ministry of Education Key Laboratory of Ecology and Resources Use of the Mongolian Plateau, Hohhot, Inner Mongolia, 010021, China.

Institutional Review Board Statement: Not applicable.

Informed Consent Statement: Not applicable.

Data Availability Statement: The datasets supporting the conclusions of this article are available in the NCBI Sequence Read Archive (SRA) repository under the project name PRJNA658710 (https: / / www.ncbi.nlm.nih.gov/sra/?term=PRJNA658710, accessed on 3 October 2021). All other datasets generated for this study are included in the article/Supplementary Material, further inquiries can be directed to the corresponding authors.

Acknowledgments: We thank Liwen Bianji, Edanz Editing China (www.liwenbianji.cn/ac) for editing the English text of a draft of this manuscript.

Conflicts of Interest: The authors declare no conflict of interest.

\section{References}

1. Bai, Y.; Huang, J.; Zheng, S.; Pan, Q.; Zhang, L.; Zhou, H.; Xu, H.; Li, Y.; Ma, J. Drivers and regulating mechanisms of grassland and desert ecosystem services. Chin. J. Plant Ecol. 2014, 38, 93-102.

2. Zhou, G.; Zhou, X.; He, Y.; Shao, J.; Hu, Z.; Liu, R.; Zhou, H.; Hosseinibai, S. Grazing intensity significantly affects belowground carbon and nitrogen cycling in grassland ecosystems: A meta-analysis. Glob. Chang. Biol. 2017, 23, 1167-1179. [CrossRef] [PubMed]

3. Song, Z.; Liu, H.; Si, Y.; Yin, Y. The production of phytoliths in China's grasslands: Implications to the biogeochemical sequestration of atmospheric $\mathrm{CO}_{2}$. Glob. Chang. Biol. 2012, 18, 3647-3653. [CrossRef]

4. Akiyama, T.; Kawamura, K. Grassland degradation in China: Methods of monitoring, management and restoration. Grassl. Sci. 2010, 53, 1-17. [CrossRef]

5. Hou, F.; Yang, Z. Effects of grazing of livestock on grassland. Acta Ecol. Sin. 2006, 26, 244-264.

6. Schlichting, C.D.; Smith, H. Phenotypic plasticity: Linking molecular mechanisms with evolutionary outcomes. Evol. Ecol. 2002, 16, 189-211. [CrossRef]

7. Chevin, L.M.; Lande, R.; Mace, G.M. Adaptation, plasticity, and extinction in a changing environment: Towards a predictive theory. PLoS Biol. 2010, 8, e1000357. [CrossRef]

8. Louault, F.; Pillar, V.D.; Aufrère, J.; Garnier, E.; Soussana, J.-F. Plant traits and functional types in response to reduced disturbance in a semi-natural grassland. J. Veg. Sci. 2005, 16, 151-160. [CrossRef]

9. Rusch, G.M.; Skarpe, C.; Halley, D.J. Plant traits link hypothesis about resource-use and response to herbivory. Basic Appl. Ecol. 2009, 10, 466-474. [CrossRef]

10. Li, X.; Hou, X.; Wu, X.; Sarula., J.L.; Chen, H.; Liu, Z.; Ding, Y. Plastic responses of stem and leaf functional traits in Leymus chinensis to long-term grazing in a meadow steppe. Chin. J. Plant Ecol. 2014, 38, 440-451.

11. Cingolani, A.M.; Posse, G.; Collantes, M.B. Plant functional traits, herbivore selectivity and response to sheep grazing in Patagonian steppe grasslands. J. Appl. Ecol. 2005, 42, 50-59. [CrossRef]

12. Matthew, C.; Lemaire, G.; Sackville, H.N.R.; Hernandez-Garay, A. A modified self-thinning equation to describe size/density relationships for defoliated swards. Ann. Bot. 1995, 76, 579-587. [CrossRef]

13. Pereira, L.E.T.; Paiva, A.J.; Geremia, E.V.; Silva, S.C.D. Grazing management and tussock distribution in elephant grass. Grass Forage Sci. 2015, 70, 406-417. [CrossRef]

14. Zhou, S.; Lou, Y.; Tzin, V.; Jander, G. Alteration of plant primary metabolism in response to insect herbivory. Plant Physiol. 2015, 169, 1488-1498. [CrossRef]

15. Liu, M.; Gong, J.; Li, Y.; Li, X.; Yang, B.; Zhang, Z.; Yang, L.; Hou, X. Growth-defense trade-off regulated by hormones in grass plants growing under different grazing intensities. Physiol. Plant. 2019, 166, 553-569. [CrossRef] [PubMed]

16. Peng, Y.; Jiang, G.; Liu, X.; Niu, S.; Liu, M.; Biswas, D.K. Photosynthesis, transpiration and water use efficiency of four plant species with grazing intensities in Hunshandak Sandland, China. J. Arid Environ. 2007, 70, 304-315. [CrossRef]

17. Zhao, W.; Chen, S.; Lin, G. Compensatory growth responses to clipping defoliation in Leymus chinensis (Poaceae) under nutrient addition and water deficiency conditions. Plant Ecol. 2008, 196, 85-99. [CrossRef]

18. Siddappaji, M.H.; Scholes, D.R.; Krishnankutty, S.M.; Calla, B.; Clough, S.J.; Zielinski, R.E.; Paige, K.N. The role of invertases in plant compensatory responses to simulated herbivory. BMC Plant Biol. 2015, 15, 278. [CrossRef] [PubMed]

19. Zhang, Z.; Gong, J.; Wang, B.; Li, X.; Ding, Y.; Yang, B.; Zhu, C.; Liu, M.; Zhang, W. Regrowth strategies of Leymus chinensis in response to different grazing intensities. Ecol. Appl. 2020, 30, e02113. [CrossRef] 
20. Sunil, B.; Saini, D.; Bapatla, R.B.; Aswani, V.; Raghavendra, A.S. Photorespiration is complemented by cyclic electron flow and the alternative oxidase pathway to optimize photosynthesis and protect against abiotic stress. Photosynth. Res. 2019, 139, 67-79. [CrossRef] [PubMed]

21. Ma, H. Influence of different grazing intensities in desert steppe on some physiological indexes of several pastures. Agric. Res. Arid Areas 2008, 26, 79-84.

22. Xiu, H.; Zhao, M.; Han, B.; Wang, J.; Niu, H.; Cheng, Y.; Han, X. The change of the amino acid content in the leaves of Agropyron cristatum under the stress of grazing. J. Anhui Agric. Sci. 2013, 41, 12045-12048.

23. Elsa, L.; Harshadrai, R.; Schweigert, F.J.; Fernando, C.eS.; Ana, F.; Rodrigues, C.A.; Célia, A.; Martinho, A.A.; Varela, C.A.; Elvira, S.-B. The effect of tannins on mediterranean ruminant ingestive behavior: The role of the oral cavity. Molecules 2011, 16, 2766-2784.

24. Hodgins-Davis, A.; Townsend, J.P. Evolving gene expression: From G to E to GxE. Trends Ecol. Evol. 2009, 24, 649-658. [CrossRef]

25. Kenkel, C.D.; Matz, M.V. Gene expression plasticity as a mechanism of coral adaptation to a variable environment. Nat. Ecol. Evol. 2016, 1, 0014. [CrossRef]

26. López-Maury, L.; Marguerat, S.; Bähler, J. Tuning gene expression to changing environments: From rapid responses to evolutionary adaptation. Nat. Rev. Genet. 2008, 9, 583-593. [CrossRef]

27. Tirosh, I.; Barkai, N.; Verstrepen, K.J. Promoter architecture and the evolvability of gene expression. J. Biol. 2009, 8, 95. [CrossRef] [PubMed]

28. Fraser, H.B.; Moses, A.M.; Schadt, E.E. Evidence for widespread adaptive evolution of gene expression in budding yeast. Proc. Natl. Acad. Sci. USA 2010, 107, 2977-2982. [CrossRef]

29. Nourmohammad, A.; Rambeau, J.; Held, T.; Kovacova, V.; Berg, J.; Lassig, M. Adaptive evolution of gene expression in Drosophila. Cell Rep. 2017, 20, 1385-1395. [CrossRef] [PubMed]

30. Lockwood, B.L.; Somero, G.N. Transcriptomic responses to salinity stress in invasive and native blue mussels (genus Mytilus). Mol. Ecol. 2011, 20, 517-529. [CrossRef]

31. Dayan, D.I.; Crawford, D.L.; Oleksiak, M.F. Phenotypic plasticity in gene expression contributes to divergence of locally adapted populations of Fundulus heteroclitus. Mol. Ecol. 2015, 24, 3345-3359. [CrossRef] [PubMed]

32. Smith, M.D.; Knapp, A.K. Dominant species maintain ecosystem function with non-random species loss. Ecol. Lett. 2003, 6, 509-517. [CrossRef]

33. Wang, X.; Chai, J.; Jiang, C.; Tai, Y.; Chi, Y.; Zhang, W.; Liu, F.; Li, S. Population spatial pattern of Stipa grandis and its response to long-term overgrazing. Biodiv. Sci. 2020, 28, 128-134.

34. Dong, K.; Hao, G.; Yang, N.; Zhang, J.; Ding, X.; Ren, H.; Shen, J.; Wang, J.; Jiang, L.; Zhao, N.; et al. Community assembly mechanisms and succession processes significantly differ among treatments during the restoration of Stipa grandis-Leymus chinensis communities. Sci. Rep. 2019, 9, 16289. [CrossRef] [PubMed]

35. Ren, H.; Schönbach, P.; Wan, H.; Gierus, M.; Taube, F. Effects of grazing intensity and environmental factors on species composition and diversity in typical steppe of Inner Mongolia, China. PLOS ONE 2012, 7, e52180. [CrossRef]

36. Li, X.; Huang, Q.; Mi, X.; Bai, Y.; Zhang, M.; Li, X. Grazing every month minimizes size but boosts photosynthesis in Stipa grandis in the steppe of Inner Mongolia, China. J. Arid Land 2018, 10, 601-611. [CrossRef]

37. Wan, D.; Wan, Y.; Hou, X.; Ren, W.; Ding, Y.; Sa, R. De novo assembly and transcriptomic profiling of the grazing response in Stipa grandis. PLOS ONE 2015, 10, e0122641.

38. Huang, X.; Peng, X.; Zhang, L.; Chen, S.; Cheng, L.; Liu, G. Bovine serum albumin in saliva mediates grazing response in Leymus chinensis revealed by RNA sequencing. BMC Genom. 2014, 15, 1126. [CrossRef] [PubMed]

39. Yan, X.; Gong, J.; Zhang, Z.; Huang, Y.; An, R.; Qi, Y.; Liu, M. Responses of photosynthetic characteristics of Stipa baicalensis to grazing disturbance. Chin. J. Plant Ecol. 2013, 37, 530-541. [CrossRef]

40. Raines, C.A. The Calvin cycle revisited. Photosynth. Res. 2003, 75, 1-10. [CrossRef]

41. Nikkanen, L.; Toivola, J.; Rintamaki, E. Crosstalk between chloroplast thioredoxin systems in regulation of photosynthesis. Plant Cell Environ. 2016, 39, 1691-1705. [CrossRef] [PubMed]

42. Feller, U.; Anders, I.; Mae, T. Rubiscolytics: Fate of Rubisco after its enzymatic function in a cell is terminated. J. Exp. Bot. 2008, 59, 1615-1624. [CrossRef]

43. Hao, D.; Ge, G.; Xiao, P.; Zhang, Y.; Yang, L. The first insight into the tissue specific Taxus transcriptome via Illumina second generation sequencing. PLoS ONE 2011, 6, e21220. [CrossRef]

44. Yan, D.; Ren, J.; Liu, J.; Ding, Y.; Niu, J. De novo assembly, annotation, marker discovery, and genetic diversity of the Stipa breviflora Griseb. (Poaceae) response to grazing. PLoS ONE 2020, 15, e0244222. [CrossRef]

45. Wang, J.; Zhao, Y.; Ray, I.; Song, M. Transcriptome responses in alfalfa associated with tolerance to intensive animal grazing. Sci. Rep. 2016, 6, 19438. [CrossRef]

46. Guo, Y.; Li, C.I.; Ye, F.; Shyr, Y. Evaluation of read count based RNAseq analysis methods. BMC Genom. 2013, 14 (Suppl. S8), S2. [CrossRef] [PubMed]

47. Schurch, N.J.; Schofield, P.; Gierliński, M.; Cole, C.; Sherstnev, A.; Singh, V.; Wrobel, N.; Gharbi, K.; Simpson, G.G.; Owen-Hughes, T. How many biological replicates are needed in an RNA-seq experiment and which differential expression tool should you use? RNA 2016, 22, 839-851. [CrossRef] [PubMed] 
48. Froussios, K.; Schurch, N.J.; Mackinnon, K.; Gierliński, M.; Duc, C.; Simpson, G.G.; Barton, G.J. How well do RNA-Seq differential gene expression tools perform in a complex eukaryote? A case study in Arabidopsis thaliana. Bioinformatics 2019, 35, $3372-3377$. [CrossRef]

49. Voelckel, C.; Gruenheit, N.; Lockhart, P. Evolutionary transcriptomics and proteomics: Insight into plant adaptation. Trends Plant Sci. 2017, 22, 462-471. [CrossRef]

50. Uematsu, K.; Suzuki, N.; Iwamae, T.; Inui, M.; Yukawa, H. Increased fructose 1,6-bisphosphate aldolase in plastids enhances growth and photosynthesis of tobacco plants. J. Exp. Bot. 2012, 63, 3001-3009. [CrossRef]

51. Westoby, M.; Walker, B.; Noy-Meir, I. Opportunistic management for rangelands not at equilibrium. J. Range Manag. 1989, 42, 266-274. [CrossRef]

52. Bai, Y.; Han, X.; Wu, J.; Chen, Z.; Li, L. Ecosystem stability and compensatory effects in the Inner Mongolia grassland. Nature 2004, 431, 181-184. [CrossRef]

53. Liang, M.; Gornish, E.S.; Mariotte, P.; Chen, J.; Liang, C. Foliar nutrient content mediates grazing effects on species dominance and plant community biomass. Rangeland Ecol. Manag. 2019, 72, 899-906. [CrossRef]

54. Fulkerson, W.J.; Donaghy, J.D. Plant-soluble carbohydrate reserves and senescence-key criteria for developing an effective grazing management system for ryegrass-based pastures: A review. Anim. Prod. Sci. 2001, 41, 261-275. [CrossRef]

55. Lin, T.; Klinkhamer, P.G.L.; Vrieling, K. Evolutionary changes in growth, regrowth and carbohydrate storage in an invasive plant. Sci. Rep. 2018, 8, 14917. [CrossRef] [PubMed]

56. McNaughton, S.J. Grazing as an optimization process: Grass-ungulate relationships in the Serengeti. Am. Nat. 1979, 113, 691-703. [CrossRef]

57. Painter, E.L.; Detling, J.K. Effects of defoliation on net photosynthesis and regrowth of western wheatgrass. J. Range Manag. 1981, 34, 68-71. [CrossRef]

58. Tito, R.; Castellani, T.T.; Fáveri, S.B.; Lopes, B.C.; Vasconcelos, H.L. From over to undercompensation: Variable responses to herbivory during ontogeny of a neotropical monocarpic plant. Biotropica 2016, 48, 608-617. [CrossRef]

59. Ruiz-R, N.; Ward, D.; Saltz, D. Leaf compensatory growth as a tolerance strategy to resist herbivory in Pancratium sickenbergeri. Plant Ecol. 2008, 198, 19-26. [CrossRef]

60. Zhang, J.; Li, Z.; Li, J.; Liu, J.; Lv, S.; Han, G. Comprehensive evaluation and correspondence analysis of nutritional value of common grass species in Ewenki Grassland. Chin. J. Grassl. 2019, 41, 33-39.

61. Dusenge, M.E.; Duarte, A.G.; Way, D.A. Plant carbon metabolism and climate change: Elevated $\mathrm{CO}_{2}$ and temperature impacts on photosynthesis, photorespiration and respiration. New Phytol. 2019, 221, 32-49. [CrossRef]

62. Yang, B.; Liu, J.; Ma, X.; Guo, B.; Liu, B.; Wu, T.; Jiang, Y.; Chen, F. Genetic engineering of the Calvin cycle toward enhanced photosynthetic $\mathrm{CO}_{2}$ fixation in microalgae. Biotechnol. Biofuels 2017, 10, 229. [CrossRef] [PubMed]

63. Tabita, F.R.; Hanson, T.E.; Satagopan, S.; Witte, B.H.; Kreel, N.E. Phylogenetic and evolutionary relationships of RubisCO and the RubisCO-like proteins and the functional lessons provided by diverse molecular forms. Philos. Trans. R. Soc. Lond. B Biol. Sci. 2008, 363, 2629-2640. [CrossRef] [PubMed]

64. Andersson, I. Catalysis and regulation in Rubisco. J. Exp. Bot. 2008, 59, 1555-1568. [CrossRef] [PubMed]

65. Genkov, T.; Meyer, M.; Griffiths, H.; Spreitzer, R.J. Functional hybrid rubisco enzymes with plant small subunits and algal large subunits: Engineered rbcS cDNA for expression in chlamydomonas. J. Biol. Chem. 2010, 285, 19833-19841. [CrossRef]

66. Bracher, A.; Starling-Windhof, A.; Hartl, F.U.; Hayer-Hartl, M. Crystal structure of a chaperone-bound assembly intermediate of form I Rubisco. Nat. Struct. Mol. Biol. 2011, 18, 875-880. [CrossRef] [PubMed]

67. Suzuki, Y.; Nakabayashi, K.; Yoshizawa, R.; Mae, T.; Makino, A. Differences in expression of the RBCS multigene family and rubisco protein content in various rice plant tissues at different growth stages. Plant Cell Physiol. 2009, 50, 1851-1855. [CrossRef]

68. Lun, V.M.; Hub, J.S.; Spoel, D.V.D.; Andersson, I. $\mathrm{CO}_{2}$ and $\mathrm{O}_{2}$ distribution in Rubisco suggests the small subunit functions as a $\mathrm{CO}_{2}$ reservoir. J. Am. Chem. Soc. 2014, 136, 3165-3171. [CrossRef]

69. Barta, C.; Dunkle, A.M.; Wachter, R.M.; Salvucci, M.E. Structural changes associated with the acute thermal instability of Rubisco activase. Arch. Biochem. Biophys. 2010, 499, 17-25. [CrossRef]

70. Lu, J.; Nawaz, M.A.; Wei, N.; Cheng, F.; Bie, Z. Suboptimal temperature acclimation enhances chilling tolerance by improving photosynthetic adaptability and osmoregulation ability in watermelon. Hortic. Plant J. 2020, 6, 49-60. [CrossRef]

71. DeRidder, B.P.; Shybut, M.E.; Dyle, M.C.; Kremling, K.A.G.; Shapiro, M.B. Changes at the 3'-untranslated region stabilize Rubisco activase transcript levels during heat stress in Arabidopsis. Planta 2012, 236, 463-476. [CrossRef] [PubMed]

72. Perdomo, J.A.; Capó-Bauçà, S.; Carmo-Silva, E.; Galmés, J. Rubisco and Rubisco activase play an important role in the biochemical limitations of photosynthesis in Rice, Wheat, and Maize under high temperature and water Deficit. Front. Plant Sci. 2017, 8, 490. [CrossRef]

73. Fukayama, H.; Mizumoto, A.; Ueguchi, C.; Katsunuma, J.; Morita, R.; Sasayama, D.; Hatanaka, T.; Azuma, T. Expression level of Rubisco activase negatively correlates with Rubisco content in transgenic rice. Photosynth. Res. 2018, 137, 465-474. [CrossRef]

74. Raines, C.A. Increasing photosynthetic carbon assimilation in C3 plants to improve crop yield: Current and future strategies. Plant. Physiol. 2011, 155, 36-42. [CrossRef] [PubMed]

75. Simkin, A.J.; Lopez-Calcagno, P.E.; Davey, P.A.; Headland, L.R.; Lawson, T.; Timm, S.; Bauwe, H.; Raines, C.A. Simultaneous stimulation of sedoheptulose 1,7-bisphosphatase, fructose 1,6-bisphophate aldolase and the photorespiratory glycine decarboxylase-H 
protein increases $\mathrm{CO}_{2}$ assimilation, vegetative biomass and seed yield in Arabidopsis. Plant Biotechnol. J. 2017, 15, 805-816. [CrossRef]

76. Bi, H.; Dong, X.; Wu, G.; Wang, M.; Ai, X. Decreased TK activity alters growth, yield and tolerance to low temperature and low light intensity in transgenic cucumber plants. Plant Cell Rep. 2015, 34, 345-354. [CrossRef]

77. Henkes, S.; Sonnewald, U.; Badur, R.; Flachmann, R.; Stitt, M. A small decrease of plastid transketolase activity in antisense tobacco transformants has dramatic effects on photosynthesis and phenylpropanoid metabolism. Plant Cell 2001, 13, 535-551. [CrossRef]

78. Haake, V.; Zrenner, R.; Sonnewald, U.; Stitt, M. A moderate decrease of plastid aldolase activity inhibits photosynthesis, alters the levels of sugars and starch, and inhibits growth of potato plants. Plant J. 1998, 14, 147-157. [CrossRef]

79. Laxa, M.; Fromm, S. Co-expression and regulation of photorespiratory genes in Arabidopsis thaliana: A bioinformatic approach. Curr. Plant Biol. 2018, 14, 2-18.

80. Messant, M.; Timm, S.; Fantuzzi, A.; Weckwerth, W.; Bauwe, H.; Rutherford, A.W.; Krieger-Liszkay, A. Glycolate induces redox tuning of photosystem II in vivo: Study of a photorespiration mutant. Plant Physiol. 2018, 177, 1277-1285. [CrossRef]

81. Miyagawa, Y.; Tamoi, M.; Shigeoka, S. Overexpression of a cyanobacterial fructose-1,6-/sedoheptulose-1,7-bisphosphatase in tobacco enhances photosynthesis and growth. Nat Biotechnol 2001, 19, 965-969. [CrossRef]

82. Husic, D.W.; Husic, H.D.; Tolbert, N.E.; Black, C.C. The oxidative photosynthetic carbon cycle or C 2 cycle. Crit. Rev. Plant Sci. 1987, 5, 45-100. [CrossRef]

83. Flügel, F.; Timm, S.; Arrivault, S.; Florian, A.; Stitt, M.; Fernie, A.R.; Bauwe, H. The photorespiratory metabolite 2phosphoglycolate regulates photosynthesis and starch accumulation in Arabidopsis. Plant Cell 2017, 29, 2537-2551. [CrossRef]

84. Ding, F.; Wang, M.; Zhang, S.; Ai, X. Changes in SBPase activity influence photosynthetic capacity, growth, and tolerance to chilling stress in transgenic tomato plants. Sci. Rep. 2016, 6, 32741. [CrossRef]

85. Timm, S.; Hagemann, M. Photorespiration-how is it regulated and how does it regulate overall plant metabolism? J. Exp. Bot. 2020, 71, 3955-3965. [CrossRef]

86. Timm, S.; Woitschach, F.; Heise, C.; Hagemann, M.; Bauwe, H. Faster removal of 2-phosphoglycolate through photorespiration improves abiotic stress tolerance of Arabidopsis. Plants 2019, 8, 563. [CrossRef] [PubMed]

87. Taler, D.; Galperin, M.; Benjamin, I.; Cohen, Y.; Kenigsbuch, D. Plant $e$ R genes that encode photorespiratory enzymes confer resistance against disease. Plant Cell 2004, 16, 172-184. [CrossRef] [PubMed]

88. Xu, H.; Zhang, J.; Zeng, J.; Jiang, L.; Liu, E.; Peng, C.; He, Z.; Peng, X. Inducible antisense suppression of glycolate oxidase reveals its strong regulation over photosynthesis in rice. J. Exp. Bot. 2009, 60, 1799-1809. [CrossRef] [PubMed]

89. Zelitch, I.; Schultes, N.P.; Peterson, R.B.; Brown, P.; Brutnell, T.P. High glycolate oxidase activity is required for survival of maize in normal air. Plant Physiol. 2009, 149, 195-204. [CrossRef]

90. Wingler, A.; Lea, P.J.; Quick, W.P.; Leegood, R.C. Photorespiration: Metabolic pathways and their role in stress protection. Philos. Trans. R. Soc. B 2000, 355, 1517-1529. [CrossRef]

91. Modde, K.; Timm, S.; Florian, A.; Michl, K.; Fernie, A.R.; Bauwe, H. High serine:glyoxylate aminotransferase activity lowers leaf daytime serine levels, inducing the phosphoserine pathway in Arabidopsis. J. Exp. Bot. 2017, 68, 643-656. [CrossRef] [PubMed]

92. Timm, S.; Florian, A.; Arrivault, S.; Stitt, M.; Fernie, A.R.; Bauwe, H. Glycine decarboxylase controls photosynthesis and plant growth. FEBS Lett. 2012, 586, 3692-3697. [CrossRef]

93. Lopez-Calcagno, P.E.; Fisk, S.; Brown, K.L.; Bull, S.E.; South, P.F.; Raines, C.A. Overexpressing the H-protein of the glycine cleavage system increases biomass yield in glasshouse and field-grown transgenic tobacco plants. Plant Biotechnol. J. 2019, 17, 141-151. [CrossRef]

94. Bai, Y.; Wu, J.; Clark, C.M.; Naeem, S.; Pan, Q.; Huang, J.; Zhang, L.; Han, X. Tradeoffs and thresholds in the effects of nitrogen addition on biodiversity and ecosystem functioning: Evidence from inner Mongolia Grasslands. Glob. Chang. Biol. 2010, 16, 358-372. [CrossRef]

95. Bai, W.; Wan, S.; Niu, S.; Liu, W.; Chen, Q.; Wang, Q.; Zhang, W.; Han, X.; Li, L. Increased temperature and precipitation interact to affect root production, mortality, and turnover in a temperate steppe: Implications for ecosystem C cycling. Glob. Chang. Biol. 2010, 16, 1306-1316. [CrossRef]

96. Wu, N.; Liu, G.; Yang, Y.; Song, X.; Bai, H. Dynamics monitoring of net primary productivity and its response to climate factors in native grassland in Inn Mongolia using a light-use efficiency model. Acta Prataculturae Sin. 2020, 29, 1-10.

97. Wang, J.; He, L.; Lu, S.; Lv, D.; Huang, T.; Cao, Q.; Zhang, X.; Liu, B. Photosynthetic vegetation cover response to precipitation on the Inner Mongolian Steppe. Acta Ecol. Sin. 2020, 40, 5620-5629.

98. Bolger, A.M.; Lohse, M.; Usadel, B. Trimmomatic: A flexible trimmer for Illumina sequence data. Bioinformatics 2014, 30, 2114-2120. [CrossRef]

99. Chen, Y.; Chen, Y.; Shi, C.; Huang, Z.; Zhang, Y.; Li, S.; Li, Y.; Ye, J.; Yu, C.; Li, Z.; et al. SOAPnuke: A MapReduce acceleration supported software for integrated quality control and preprocessing of high-throughput sequencing data. GigaScience 2018, 7, 1-6. [CrossRef]

100. Grabherr, M.G.; Haas, B.J.; Yassour, M.; Levin, J.Z.; Thompson, D.A.; Amit, I.; Adiconis, X.; Fan, L.; Raychowdhury, R.; Zeng, Q.; et al. Trinity: Reconstructing a full-length transcriptome without a genome from RNA-Seq data. Nat. Biotechnol. 2011, 29,644 . [CrossRef] 
101. Pertea, G.; Huang, X.; Liang, F.; Antonescu, V.; Sultana, R.; Karamycheva, S.; Lee, Y.; White, J.; Cheung, F.; Parvizi, B.; et al. TIGR Gene Indices clustering tools (TGICL): A software system for fast clustering of large EST datasets. Bioinformatics 2003, 19, 651-652. [CrossRef] [PubMed]

102. Simão, F.A.; Waterhouse, R.M.; Ioannidis, P.; Kriventseva, E.V.; Zdobnov, E.M. BUSCO: Assessing genome assembly and annotation completeness with single-copy orthologs. Bioinformatics 2015, 31, 3210-3212. [CrossRef] [PubMed]

103. Langmead, B.; Salzberg, S.L. Fast gapped-read alignment with Bowtie 2. Nat. Methods 2012, 9, 357-359. [CrossRef]

104. Li, B.; Dewey, C.N. RSEM: Accurate transcript quantification from RNA-Seq data with or without a reference genome. BMC Bioinform. 2011, 12, 323. [CrossRef] [PubMed]

105. Gómez-Rubio, V. ggplot2-elegant graphics for data analysis (2nd Edition). J. Stat. Softw. 2017, 77, 1-3. [CrossRef]

106. Conesa, A.; Götz, S.; Garcia-Gomez, J.M.; Terol, J.; Talón, M.; Robles, M. Blast2GO: A universal tool for annotation, visualization and analysis in functional genomics research. Bioinformatics 2005, 21, 3674-36766. [CrossRef]

107. Wang, L.; Feng, Z.; Wang, X.; Wang, X.; Zhang, X. DEGseq: An R package for identifying differentially expressed genes from RNA-seq data. Bioinformatics 2010, 26, 136-138. [CrossRef]

108. Benjamini, Y.; Hochberg, Y. Controlling the false discovery rate: A practical and powerful approach to multiple testing. J. R. Stat. Soc. Ser. B Stat. Methodol. 1995, 57, 289-300. [CrossRef]

109. Storey, J.D.; Tibshirani, R. Statistical methods for identifying differentially expressed genes in DNA microarrays. Methods Mol. Biol. 2003, 224, 149-157. [PubMed]

110. Howe, E.A.; Sinha, R.; Schlauch, D.; Quackenbush, J. RNA-Seq analysis in MeV. Bioinformatics 2011, 27, 3209-3210. [CrossRef]

111. Thimm, O.; Bläsing, O.; Gibon, Y.; Nagel, A.; Meyer, S.; Krüger, P.; Selbig, J.; Müller, L.A.; Rhee, S.Y.; Stitt, M. MAPMAN: A user-driven tool to display genomics data sets onto diagrams of metabolic pathways and other biological processes. Plant J. 2004, 37, 914-939. [CrossRef] [PubMed]

112. Wan, D.; Wan, Y.; Yang, Q.; Zou, B.; Ren, W.; Ding, Y.; Wang, Z.; Wang, R.; Wang, K.; Hou, X. Selection of reference genes for qRT-PCR analysis of gene expression in Stipa grandis during environmental stresses. PLoS ONE 2017, 12, e0169465. [CrossRef] [PubMed] 